\title{
Divergent Growth Trajectories in China's Chemical Industry: The Case of the Newly Developed Industrial Parks in Shanghai, Nanjing and Ningbo
}

\author{
Gang Zeng \& Harald Bathelt
}

\author{
Version Post-print/accepted manuscript \\ Citation Zeng, G., \& Bathelt, H. (2011). Divergent growth trajectories in China's \\ (published version) chemical industry: the case of the newly developed industrial parks in \\ Shanghai, Nanjing and Ningbo. GeoJournal, 76(6), 675-698.
}

Copyright / License

Publisher's Statement The final publication is available at Springer via http://dx.doi.org/ 10.1007/s10708-009-9313-6

Always cite the published version, so the author(s) will receive recognition through services that track citation counts, e.g. Scopus. If you need to cite the page number of the TSpace version (original manuscript or accepted manuscript) because you cannot access the published version, then cite the TSpace version in addition to the published version using the permanent URI (handle) found on the record page. 


\title{
Divergent Growth Trajectories in China's Chemical Industry: The Case of the Newly Developed Industrial Parks in Shanghai, Nanjing and Ningbo
}

\author{
by \\ Gang Zeng \\ East China Normal University, Department of Human Geography, \\ 3663 North Zhongshan Road, Shanghai 200062, China, \\ E-mail: gzeng@re.ecnu.edu.cn \\ and \\ Harald Bathelt \\ University of Toronto, Department of Political Science and Department of Geography, \\ Sidney Smith Hall, 100 St. George Street, Toronto ON M5S 3G3, Canada, \\ E-mail: harald.bathelt@utoronto.ca, URL:http://www.harald-bathelt.com
}

Paper Submitted to

GeoJournal 


\title{
Divergent Growth Trajectories in China's Chemical Industry: The Case of the Newly Developed Industrial Parks in Shanghai, Nanjing and Ningbo
}

\begin{abstract}
In the late 1990's, the "new-economy" industries in China proved to be relatively vulnerable and were strongly hit by the financial crisis in Asia. As a result, a new economic support policy was introduced in China's Yangtze Delta region, which put greater emphasis on the support of traditional industrial sectors, including the chemical industry. This paper investigates the effects of the growth of this industry, as well as the potential and current problems emerging from new growth paths. It compares the growth of three newly developed chemical industry parks in Shanghai, Nanjing and Ningbo. The paper is based on an institutional perspective of clustering processes arguing that regional industrialization is subject to formal and institutional arrangements which shape the growth paths and contribute to divergent regional trajectories. Although these industrial parks all benefit from the general economic upswing in China, their development is influenced by different business models, economic contexts, goals and strategies, leaving room for divergence and specialization. Due to the existing structure of operations, these parks have a great deal of potential but also face substantial challenges, such as the establishment of internal networks and close customer linkages. It is argued that this might limit their innovative capability in the future. Furthermore, their growth prospects differ depending on future government policies.
\end{abstract}

Keywords: industrial parks, chemical industry, Shanghai, Nanjing, Ningbo, divergent growth trajectories 


\section{Introduction}

During the 1990s, the new goal of economic policy in the larger Shanghai and surrounding Yangtze Delta region was to support the shift from traditional manufacturing sectors, based on large state-owned firms, toward the new industries and services of the knowledge economy. However, as the financial crisis in Asia indicated following 1997, the new economic core sectors were quite vulnerable. This crisis slowed down economic growth, led to a reduction in domestic wealth, disrupted existing economic development plans, and contributed to increased social instability (Zeng 2000; 2001). Due to this unexpected economic downswing, the goals of economic policies changed. Policy makers felt that it was premature to concentrate primarily on the industries of the "new economy" and, instead, placed greater emphasis on "old economy" industries, such as machinery and automobile production (e.g. Depner and Bathelt 2005), as well as the chemical industry including pharmaceuticals.

Taking this policy shift as the starting point of our inquiry, this paper investigates its effects on the chemical industry in the Yangtze Delta region. We aim to demonstrate how strong governmental support, combined with continuous foreign direct investment in a high-growth environment, can instigate new economic development paths. Through an examination of three newly developed chemical industry parks in Shanghai, Nanjing and Ningbo, the goal of this study is to determine whether increased support and investment have given rise to the development of new industry clusters, and how this policy shift impacts the social and regional divisions of labor in the Yangtze Delta region. To this end, we investigate the evolution of the three industrial parks and the goals behind their development. Furthermore, we analyze the industry structure, institutional context and structure of social relations within these parks, as well as their linkages with international markets. This work draws from a cluster conception (Bathelt, Malmberg and Maskell 2004; Bathelt and Zeng 2005) which emphasizes the importance of an institutional perspective. It argues that initial clustering processes are subject to formal and institutional arrangements that shape the regional growth paths and contribute to the establishment of different or divergent regional trajectories. The empirical analysis clearly shows that the chemical industry, which did not have a high priority in economic development during the 1990s, experienced tremendous growth since 2000 . The case studies conducted also provide strong evidence that new regional divisions of labor and intra-regional rivalry developed between different locations, despite the general growth tendency. 
This paper is organized as follows. The next section lays out the conceptual foundation of the study based on a cluster conception. Using a multi-dimensional framework, it argues that strong producer-user linkages within and across regions and a supportive institutional environment are necessary to exploit growth potentials. Section 3 outlines the study's methodological approach. Sections 4 through 6 offer an empirical analysis of the economic structure and development of the newly established Shanghai Chemical Industry Park (SCIP), Nanjing Chemical Industry Park (NCIP) and Ningbo Chemical Industry Zone (NCIZ), respectively. We conclude in section 7 by summarizing and comparing the growth of the three chemical industry parks, and by making some preliminary predictions regarding their likelihood of developing into new industry clusters. This section also identifies benefits and challenges of this growth for the divisions of labor in the Yangtze Delta region.

\section{Clusters, Institutions and Divergent Growth Trajectories}

A field of substantial debate, which has been key to the development of economic geography, is that of understanding and explaining industrial agglomeration and developing policies to produce or maintain such concentrations. Porter's (1990) introduction and discussion of the cluster concept in many ways served to push the debate surrounding agglomeration further, and revived older debates on industrial location. This work was also decisive in strengthening the policy relevance of clusters and related concepts, which are now widely used to support regional and national economic development policies. That being said, the degree to which different selfproclaimed cluster policies are actually based on the same model remains unclear, as the link between academic conceptualization and policy formulation is often weak (Martin and Sunley 2003).

Situating our research within the context of this debate, this paper views clusters as regional concentrations of firms belonging to a value chain, and their service infrastructure, which are linked through traded and untraded interdependencies (Malmberg and Maskell 2002; Pinch, Henry, Jenkins and Tallmann 2003; Bathelt 2005). To provide a better understanding of the growth and reproductive capabilities of clusters, we suggest distinguishing different cluster dimensions which help identify their strengths and/or weaknesses. The horizontal and vertical cluster dimensions are important because they impact cooperation, interactive learning and product differentiation within a cluster (Porter 1998; Enright 2003; McCann 2008). The vertical 
dimension encompasses firms with complementary products and competencies which benefit from intensive transactions within a cluster and form networks of traded interdependencies. Vertical linkages are associated with producer-user interaction and respective learning processes. The horizontal dimension refers to firms that produce similar products (Maskell and Lorenzen 2004) establishing the grounds for local rivalry and product differentiation based on learning by observation. Both dimensions are important for the formation of specialized regional labor markets (Malmberg and Power 2003). The external dimension of a cluster is important because it provides connections with global markets, technologies and knowledge pools which enable ongoing economic growth (Bathelt, Malmberg and Maskell 2004).

In addition to these dimensions, institutional arrangements and power relations establish further important dimensions that support reproductivity and coherence within a cluster (Bathelt and Zeng 2005). This paper particularly emphasizes the role of different institutional configurations in shaping the structure of cluster relations. Along with Setterfield (1993), we view institutions as correlated behavior of economic agents, or stabilized patterns of social relations (Bathelt and Glückler 2003). Within this framework, two types of institutions jointly shape economic patterns and decision-making: formal and informal institutions: While formal institutions are related to economic interaction based on conventions, norms, traditions, experience, trust or reciprocity which are often tacit in nature -, formal institutions are related to laws, rules or regulations which are codified. A joint institutional framework allows specialized users and producers to discuss and solve particular problems, and develop reasonable expectations regarding each other's actions (Hodgson 1988; North 1990). The creation of institutions within a cluster helps to stabilize producer-user relations, shapes the nature of economic decisions and impacts the overall growth trajectory of a cluster (Bathelt 2005; Bathelt and Zeng 2005).

Although cluster dimensions also exist in agglomerations of the chemical industry, the structure of supplier relations is somewhat different from that found in other industries. Regional producer-user networks tend to be more narrow in character and do not involve intensive horizontal and vertical interaction. Suppliers establish close transactional relations with their main customers, but often do not engage in intensive interaction or joint product development. These relationships often appear to be relatively standardized, but are stable as the firms specialize in the complex production of chemicals that are sometimes dangerous to handle and expensive to transport (Bathelt 1997). Overall, we do not expect that the development of clusters 
within the chemical industry has the same structure as that found in other industries. Nonetheless, the development of regional clusters is, either implicitly or explicitly, the goal of many economic policies that establish specialized industrial parks and design their institutional set-up. The establishment of chemical industry parks in the Yangtze Delta region serves as a good example of this. Here, new industrial parks have recently been built that focus on the production of petrochemicals and organic chemicals. The strategy of these parks is to select and attract firms from a value chain to develop close transactional networks and, through this, spur broader economic growth.

From this discussion, we are skeptical that fully-fledged clusters could be established in the Yangtze Delta chemical industry. We can expect, however, that initial clustering or agglomerating may occur as a result of the enormous investments undertaken in the industry. These include investments by the central and provincial governments and by large state-owned chemical firms, as well as substantial foreign direct investments. Although knowledge regarding the origins and initial stages of cluster development is still limited (e.g. Feldman and Francis 2004; Henn 2006; Atherton and Johnston 2008), it is important to consider that such development is fundamentally shaped and directed by the specific institutional conditions that exist within the regions. These vary substantially within the Yangtze Delta region and find expression in different local traditions and business cultures. The province of Zhejiang with Ningbo, for instance, developed a network of entrepreneurs that started up many successful ventures involving substantial risks, especially since the Chinese economy opened up (Wei, Li and Wang 2007). These businessmen formed close guanxi networks through which they were able to split risks but also mobilize large amounts of private capital for economic projects. Due to these private initiatives, the provincial and central governments played a limited role in economic development. In contrast, Nanjing, which is located in the province of Jiangsu, was dominated by large stateowned firms with strong linkages to the central and provincial governments (Ong 2007). In the chemical industry, these dominant firms aimed to protect their leadership within China through close business-state relations, while private risk-taking was less common than in Zhejiang. Shanghai also had a strong tradition of large state-owned firms that developed close government linkages, especially with the provincial government. In the late 1990s, however, the focus radically shifted toward an opening policy based on the integration of foreign direct investment, technology transfer and the embedding of western business cultures (Wang 1996). 
Related to specific institutional settings, we can expect that initial clustering tendencies may lead to different growth trajectories. Due to the impact of varying formal and informal institutions, different types of decisions and interaction patterns are favored in different regions. As demonstrated in the empirical sections below, the formal institutional conditions related to the nature of investments, basic infrastructure provided, and governmental policies were quite different between the three case studies. We further show that the dominance of certain informal institutional arrangements also had a substantial impact on how firms acted and what decisions were made, especially related to the chemical operations and interaction patterns that were attracted. These informal institutions were closely related to the different business models found. From the above argument, we derived two hypotheses for our research on the development of the chemical industry in the Yangtze Delta region: Our first hypothesis is that it is unlikely that fullydeveloped industry clusters with close social relations between local firms will develop. Our second hypothesis is that differences in the institutional context of the regions will spur different cluster structures and developments despite similarities in the product range. Key factors that assist us in analyzing and comparing potential cluster configurations and their institutional set-up include the type of industrial park and infrastructure set up, goal of development and cluster policy, firm structure and investments, as well as producer-user linkages. Before analyzing these indicators systematically in each case study region, the methodology of this research is discussed in the next section.

\section{Methodology}

Our research draws upon a variety of information and data sources, including statistical data, academic literature, business/news reports and government publications. More importantly, it is based on a qualitative research design that we developed to analyze the processes and motivations behind the establishment and development of chemical industry parks in the Yangtze Delta region, as well as their structure of internal and external social relations. In particular, our research design involved semi-structured interviews that were conducted between September 2003 and June 2007. The three most important industry parks in Shanghai, Nanjing and Ningbo were chosen as cases for this work. We conducted up to two interviews in different years with park developers and a sample of Chinese, German and other foreign (mainly European) chemical firms. In addition, we conducted interviews with industry observers, such as former managers in 
the industry, and other chemical firms throughout the Yangtze Delta region. In total, we conducted over 50 interviews with representatives of firms and local experts in the larger Shanghai region and in Wuxi, Nanjing and Ningbo.

This paper particularly draws on 20 interviews with agents in the three chemical industry parks investigated. These agents were not chosen randomly. Instead, we used the following sampling strategy to get an overview of the most important trends in the chemical industry. First, we contacted the park developers and conducted interviews with them about the origins, goals and structures of the parks. Second, we contacted the most significant foreign investors in each industrial park. Third, we approached the largest Chinese and foreign-Chinese joint venture firms. Lastly, we used leads from the earlier interviews to select small and medium-sized Chinese chemical firms located in the parks. About $80 \%$ of the firms contacted agreed to participate in this research project and were willing to arrange for an interview.

In our interviews, we talked to the general managers, chief executive officers, or foreign expatriate researchers or managers of these firms. The interviews with Chinese firms were usually done in Chinese and translated into German. All other interviews were done in German or English. With the exception of those interviews conducted with Chinese managers, all interviews were recorded on tape and transcribed. The transcriptions were further restructured according to the main questions regarding cluster structure and development. They were intensively discussed between both authors who conducted most interviews jointly, and triangulated with other available information. Chinese interviews were recorded in the form of detailed protocols in German and Chinese. The protocols were subsequently compared with one another and adjusted to avoid misinterpretations. Despite the limited number of interviews upon which our analysis is based, we are confident that this study captures many of the core tendencies in the chemical industry of the Yangtze Delta region. The data were analyzed in the form of "thick description" in an attempt to identify and describe the processes that occurred, and other data and sources were added (Miles and Huberman 1984; Silverman 2001).

The interview guide that was used had to be adjusted to the context of the interviewees, that is, to the national origin of the firms and to the position of the interviewees within the firms. The questions asked were mostly open-ended, with a few variables requiring quantitative estimates (e.g. employment, sales, percentage of regional sales and purchases). The interviews lasted between 60 and 90 minutes. In the case of foreign investors, the interviews began with an 
analysis of the start-up processes, involving questions of why, when and how decisions to establish production facilities in the region were made. This also included questions about their prior experience in China. The next set of questions revolved around producer-user relations, focusing on the main locations and structure of interactions with customers, suppliers and machinery providers. Finally, questions about experiences with Chinese joint-venture partners, business contacts and employees were posed and personal evaluations of the development prospects of the regional chemical industry requested. Interviews with Chinese firms were structured in a similar way, although the questions focused more on contacts and experiences with foreign partners and the business conduct of foreign managers. The guide for the interviews with industrial experts and park developers had to be modified as well, but covered the same major segments.

In the next section of the paper, we provide an overview of the history and growth of the chemical industry in China and the Yangtze Delta region, before turning to a closer analysis of the empirical findings of our research.

\section{Growth of the Chemical Industry in China and the Yangtze Delta Region}

Since the economic reforms and opening policy, China experienced strong economic growth. This growth was largely due to continued industrialization, which began in the 1980s and accelerated during the 1990s and 2000s associated in particular with large foreign direct investments. Although largely unexplored in academia, it is important to note that the chemical industry played a central role in this process (Dong 2007). Based on gross industrial output, the chemical industry ranks fourth after the information technology, iron/steel and machinery industries. Considering the present economic dynamics, it is foreseeable that the chemical industry will continue to grow in importance, at least in the short to medium-term (Sun and Gu 2004). It is estimated that China will be the second largest producer of chemical products after the US by the year 2015 (Perlitz 2005; Hang 2007). The history of this industry dates back much longer, however, and can be traced back to the establishment of the People's Republic. The development of the industry was closely related to the production of petrochemicals and organic 
basic chemicals. According to the economic development paths and policy initiatives, four development stages can be distinguished: ${ }^{1}$

(i) 1949-1962. Initially, China largely depended on the import of all sorts of chemical products, since a strong domestic industry base did not exist. Before the establishment of the People's Republic, only a few petrochemical firms existed in Yumen, Yanchang, Jinzhou and Jinxi (Yang 2006). After 1949, these were turned into state-owned corporations (Cheng and Bennett 2007). In 1954 and 1956, two more petrochemical plants were founded in Jinlin and Lanzhou. At this time, chemical production was heavily concentrated in the northeastern/northwestern parts of the country.

(ii) 1963-1977. The discovery and development of new oil fields in the northern/northeastern parts of China led to the formation of numerous new firms. These resources were important in the early industrialization phase of the country. First, new state-owned firms were established in Daqing, Shenli and Dagang, close to resource sites (Yang 2006). Later, high demand led to new firm formation in Beijing and Guangzhou. The locations of the chemical industry were still concentrated in China's northeastern, northwestern and northern parts, strongly influenced by established resource sites and the major sites of heavy industries.

(iii) 1978-1997. Similar to the process in other industries, economic liberalization created substantial growth impulses for the chemical industry. For the first time since the establishment of the People's Republic, the focus of national policies centered on supporting economic production, rather than on social cohesion or national unity. At this stage, new large chemical firms were founded in Jinan, Daqing, Jinshan (Shanghai), Nanjing, Maoming (Guangdong), Jilin, Fushun, Tianjin and Panjin. The locations of the industry were now closely tied to major economic centers (Hang 2007). In addition, former state-owned firms were privatized and transformed into publicly-traded firms. The goal of this transformation was to make these firms more profitable since many state-owned firms suffered from substantial losses and low efficiency, despite the new economic situation and easier market access (Cheng and Bennett 2007). Many of the new private firms had a state organization as their major shareholder, indicating that state linkages were still very strong. Cao, Qian and Weingast (1999) referred to this process as

\footnotetext{
${ }^{1}$ Due to issues of data availability and reliability, we feel only confident presenting data of the Chinese chemical industry after 1980 .
} 
"privatization, Chinese style". In the following years, the creation of township and village enterprises was also encouraged, leading to a third type of firms. Along with the increasing demand, the industry grew quickly leading to a strong increase in the number of firms, employment and gross production value. Particularly the number of small and medium-sized firms increased substantially. From 1982 to 1997, employment in the Chinese chemical industry grew by $155 \%$ from 3.1 to 7.9 million people (Table 1 ).

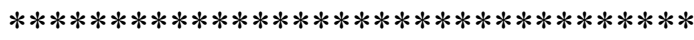

Insert Table 1 about here

The Yangtze Delta region² (Figure 1), which forms the geographical context of this study, also benefited from this development. Its large cities developed into major economic centers in China, witnessing substantial growth in the chemical industry, as well as other industries. Although the region was already an important site of chemical production before the economic reforms began, its development toward large-scale chemical production occurred especially in the late 1990s. Many multinational chemical firms, especially from Europe, began establishing production facilities in the country in the late 1980s (Mueller 2005; Mu 2006) and further extended their production base later on (Perlitz 2005). As a consequence, the gross production value of the Yangtze Delta chemical industry increased from 19.9 billion Yuan (2.5 billion US- $\$)^{3}$ to 302.5 billion Yuan (37.8 billion US-\$) between 1983 and 1997. The region's share of the total Chinese gross production value in the chemical industry remained constant, however, at about $26 \%$ (Table 2).

$* * * * * * * * * * * * * * * * * * * * * * * * * * * * * * * * * *$

Insert Figure 1 and Table 2 about here

${ }^{2}$ The region covers the three provinces of Shanghai, Jiangsu und Zhejiang, and includes the 16 major cities of Shanghai, Nanjing, Hangzhou, Ningbo, Jiaxin, Huzhou, Taizhou/Jiangsu, Zhoushan, Suzhou, Wuxi, Changzhou, Zhenjiang, Yangzhou, Shaoxing, Nantong, and Taizhou/Zhejiang.

${ }^{3}$ Throughout this paper, we used the following exchange rates: 1 US- $\$=8$ Yuan (up to 2005)/7.5 Yuan (2006)/7 Yuan (2007). 
(iv) Since 1998. With further industrialization and liberalization, China became a vibrant economy in the globalization process of the chemical industry (China Petroleum and Chemical Industry Association 2007b). On the one hand, foreign direct investments continued to grow particularly focused on the coastal areas. On the other hand, the Chinese government invested a lot of money into the extension of the chemical industry. This became even more pronounced in the aftermath of the 1997 financial crisis in Asia which hit the Chinese economy hard. The financial crisis abruptly stopped the hype surrounding the "new economy" and led the Chinese government to rethink its former prioritization of knowledge-intensive, advanced services over traditional manufacturing. As a result, new policies were implemented to further open up the Chinese economy and direct growth to include "old economy" industries (Zeng 2000; 2001). Due to this policy focus, the Chinese chemical industry grew at a fast pace. From 1997 to 2006, gross production value increased from 1164.0 billion Yuan (145.5 billion US-\$) to 5293.5 billion Yuan (705.8 billion US-\$) (Table 1). Although privatization had previously been viewed as a means toward higher profitability, as it turned out, this policy did not automatically result in improved economic performance. Indeed, many of the privatized firms remained unprofitable despite the overall growth of the economy. As Cheng and Bennett's (2007) study illustrates, industrial mergers and the establishment of core capabilities were seemingly more effective ways to gain profitability than privatization alone. Employment in the chemical industry declined during this phase as a result of two factors: First, many small and medium-sized private and collective chemical firms were closed down due to environmental problems and resource scarcity. Second, older facilities were increasingly modernized. Consequently, employment in the Chinese chemical industry decreased by more than a third from 7.9 to 5.0 million people between 1997 and 2006. Since about 2000, employment levels stabilized again due to the establishment of new domestic and foreign chemical firms which compensated for job losses related to plant closures and rationalization.

Overall, economic growth had a strong impact on the development of the chemical industry in the Yangtze Delta region where large shares of the industrial users were concentrated ( $\mathrm{Mu} 2006)$. The chemical industries in Nanjing, Shanghai and Ningbo increased in national importance, and the Jiangsu, Shanghai and Zhejiang provinces developed into major locations of this industry. Between 1997 and 2006, the gross production value in the region grew from 302.5 billion Yuan (37.8 billion US-\$) to 1,603.1 billion Yuan (213.7 billion US-\$) (Table 2). Its national share in employment and gross production value increased from $15.5 \%$ to $17.6 \%$ and from $25.9 \%$ to 
$30.3 \%$, respectively (Table 3; Table 2). Depending on the chemical branch, between $16.7 \%$ (petroleum processing, coke products and processing of nuclear fuels) and $71.4 \%$ (chemical fibers) of the total Chinese production value were produced in the Yangtze Delta region in 2006 (Table 4). Chemical industry parks were established in several cities, such as Shanghai, Nanjing, Wuxi, and Ningbo, and received considerable support from the central, provincial, and local governments. It was also suggested that another huge (50 km long) chemical industry zone should be established in the province of Jiangsu. This project was, however, not approved by the central government due to environmental concerns (Sun and $\mathrm{Gu} 2004$ ).

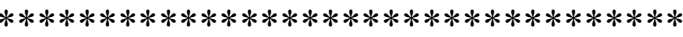

Insert Table 3 and Table 4 about here

$* * * * * * * * * * * * * * * * * * * * * * * * * * * * * * * * * *$

In addition to the growth of customer industries, the chemical industry in the Yangtze Delta region also benefited from improvements in infrastructure and investments in new projects. Some cities had access to deep sea harbors, while others benefited from the possibility of conducting bulk shipments on the Yangtze River. As a consequence, chemical firms had improved access to raw materials, especially crude oil from regions such as the Near East, Africa and Indonesia. Nanjing was also equipped with an oil pipeline that connected the region to the northern Chinese oil fields (Zhong 2007). Due to the enormous growth of manufacturing industries, such as information technology and automobiles whose production value in China grew by almost $540 \%$ between 1995 and 2004 (National Bureau of Statistics of China 2006a), the demand for chemical products remained very high. In addition, the developments of the financial markets and cooperation with foreign firms were important in providing access to investment capital.

In the late $2000 \mathrm{~s}$, however, the central government began to revise its support policies of the chemical industry in light of global warming and environmental protection (China Petroleum and Chemical Industry Association 2006). Even though some provincial and city governments still actively supported the development of a regional petrochemical industry, the central government has reduced its incentives for the expansion of this industry in favor of service industries (Wu 2005). ${ }^{4}$ In terms of the spatial distribution of the chemical industry, the central government also

\footnotetext{
${ }^{4}$ Of course, drastic increases in oil prices in the future associated with the consequences of "peak oil" could have a drastic effect on the growth path of the Chinese, as well as the global, chemical industry (e.g. Schiller 2008; Wan
} 
began to favor relocations or, at least, shifts of primary growth areas from the heavily populated Yangtze Delta city-regions to China's southwestern regions. The main objective was to stimulate economic development in less developed regions while, at the same time, reducing financial incentives for foreign direct investment in the coastal areas.

How all of these factors have materialized into new industrial centers is investigated in the three subsequent sections that focus on the evolution of the newly developed industrial parks/zones in Shanghai, Nanjing and Ningbo. Our study emphasizes an institutional perspective to understand the development of specific regional growth trajectories. Drawing on the cluster conception presented above (Bathelt 2005; Bathelt and Zeng 2005), our analysis of the chemical industry parks presents what we refer to as "thick description" of the industry structure of three cases and their institutional set-up, especially in terms of formal institutions. This includes the analysis of the park structure, cluster policy and goal of development, nature of firms and investments, and producer-user linkages. Through this, we aim to elaborate the social foundations of economic growth and potential cluster development in the Yangtze Delta region. This also provides the foundation for our discussion of the divergent growth paths of the three industrial parks in the concluding section of this paper.

\section{Integrated Large-Scale Investments in the Shanghai Chemical Industry Park (SCIP) since 2004}

The institutional conditions for the growth of the chemical industry in the SCIP were quite unique as this was a greenfield development of a huge scale that would be difficult to realize in the context of other countries, especially in Europe and North America.

Park structure: Since 2004, the SCIP developed into a modern world-scale industrial site for chemical production. It has a size of about $7 \mathrm{~km}$ by $4 \mathrm{~km}$, totaling $29.4 \mathrm{~km}^{2}$. The industrial park is located in Caojing about 50-60 km south of Shanghai's city center, at the north side to Hangzhou Bay (Festel and Geng 2005; Krumberger 2005; Shanghai Chemical Industry Park Development Co. 2004; 2007). The SCIP has direct access to the Pacific Ocean (Figure 1; Figure 2). Shipments of crude oil or basic chemicals can be received via integrated jetties and harbor facilities. The 
park is a fully developed industrial area equipped with infrastructure, such as streets, internal pipelines, public utilities and environmental protection facilities, all of which were provided by the Shanghai Chemical Industry Park Development Corporation, which operates and manages the park. The SCIP, as well as the chemical industry parks in Nanjing and Ningbo, mirror not only the pace of economic growth in China, but also existing visions about the industrial future of the country. The northern half of the SCIP $\left(13.4 \mathrm{~km}^{2}\right)$ is located on sediments of the Yangtze River, while the southern part $\left(10.0 \mathrm{~km}^{2}\right)$ is located on land that was reclaimed from the Hangzhou Bay through embankment and the installation of drainage systems. The southwestern part $\left(6.0 \mathrm{~km}^{2}\right)$ was not yet fully drained at the time of our last visit in 2006. Once completed, this section will connect the SCIP with an older petrochemical park in Caohejing, which is located in the west. This existing industrial area consists of older facilities of large Chinese chemical/petrochemical groups. At the time of our research, linkages between these facilities and the new developments in the SCIP were virtually non-existent.

Insert Figure 2 about here

Goal of development: The goal of the development corporation was to develop the SCIP into an integrated site of petrochemical/organic chemical production and to provide a basis for the continued growth of the manufacturing sector in China. Further, the aim was to turn the park into a central hub of the chemical industry throughout Southeast Asia. The design and strategic planning of the SCIP was based on an analysis of chemical industry parks in Europe and North America. According to one executive of the development corporation, five key findings were derived from this analysis. First, petrochemical production and subsequent processing stages apparently move from raw material locations toward market locations. Second, many locations worldwide extend value chains by adding upstream and downstream operations. Third, production is increasingly carried out in large specialized facilities in order to exploit economies of scale. Fourth, the consequence of this is that multinational firms tend to develop network relations and partnerships with one another, instead of competing against each other. Fifth, environmental factors gain in importance. The concept of the SCIP was designed to incorporate these trends. At the same time, the industrial park was also supposed to become a counterweight 
to existing locations of chemical production in China, for instance competing against petrochemical operations in Nanjing.

As a result, the SCIP was designed to host an extended production chain based on petrochemical/chemical production. First, an ethylene cracker was built that formed the heart of the SCIP producing basic organic chemicals. In selecting new investment projects, the development corporation prioritized operations that established long-term material linkages with other facilities in the park in order to process basic chemicals further. Second, the institutional set-up was done in a way such as to offer a large variety of services to the tenants in the park. The logistical infrastructure for the supply and delivery of chemical goods also had a high priority. Third, the park aimed to pursue an integrated environmental protection strategy. As part of this, the energy supply in the SCIP was scheduled to be based on natural gas. Furthermore, new investors were required to install modern low-emission technologies; waste water was collected and cleaned; and a green belt was to be built. The development corporation negotiated and mediated the park relations and expansion policies with near-by farmers, residents and other agents. ${ }^{5}$ Fourth, the park management aimed to develop into an integrated agency that dealt with all problems and requests from local firms through a one-stop service philosophy (Shanghai Chemical Industry Park Development Co. 2004; 2005). Representatives of the development corporation emphasized that the growth of the park was not supposed to be based on low-cost production, but rather on its integrated long-term conception. One of the means through which to establish initial trust with new tenants was to engage some of the long-term service providers and suppliers of the new firms in ongoing infrastructure projects. The provincial government was also directly involved in and supportive of the development of the park and had a permanent on-site office. In sum, the SCIP was designed to develop into a cluster-type structure similar to that described by Malmberg and Maskell (2002) or Bathelt (2005). As will be argued below, however, it remained unclear whether a fully developed cluster would be a realistic expectation for further growth.

Firm structure and investments: At the time of our first visit in 2004, there was only one older Chinese chemical firm in full operation. In addition, there were about 20 small or medium-sized

\footnotetext{
${ }^{5}$ A representative of the development corporation emphasized that they wanted to avoid conflicts with local residents, which had been a problem in the case of BASF's investment in Nanjing.
} 
firms from other industries. Many new facilities were under construction, including foreign investments by Air Liquide, BASF, Bayer, BP, Degussa and Huntsman, as well as investments by Chinese groups such as Sinopec, SPC (Shanghai Petrochemical Corporation) and GPCC (Gaoqiao Petro-Chemical Corporation). Many projects were joint ventures of foreign-Chinese co-leadership. In 2004, Bayer officially opened its first operations in the SCIP (Shanghai Chemical Industry Park Development Co. 2004). The firm's overall investment into six new plants was viewed as a major trigger for the development of the industrial park. As interviews with representatives of different firms suggested, the firm's decision to locate in Shanghai was driven not only by an interest in developing the Chinese market; the Shanghai location was also designed to develop into the firm's major center for production and decision-making in Asia. The SCIP was an attractive site because of its central location, logistics infrastructure, the fast growing regional and national market, as well as cost advantages. The total investment made by Bayer in the SCIP was about 3.1 billion US-\$.

The only older chemical plant in the park that existed prior to 2004 was a Chinese firm that was originally located in Shanghai's Changning district. The firm had some 500 employees and sales of about 313.8 million Yuan (39.2 million US-\$). The park management was apparently not very pleased about hosting this firm (Shanghai Economic Commission, Shanghai Municipal Statistics Bureau and Shanghai Development Park Association 2004). One interviewee described its technologies as outdated and environmentally problematic. Although another observer mentioned that one of the goals was to relocate plants from inner-city locations in Shanghai to the SCIP, negative experiences with this relocation process seemed to extinguish any interest in pursuing this strategy further.

The structure of the SCIP will drastically change in the future as more chemical production facilities will be under operation. In 2006, the park already hosted 14 chemical firms with a labor force of 3,250 employees. The firms had total sales of 29.0 billion Yuan (3.6 billion US-\$) and paid taxes of 675.2 million Yuan (84.4 million US-\$) (Shanghai Economic Commission, Shanghai Municipal Statistics Bureau and Shanghai Development Park Association 2007). By 2007 , contracts for investment projects of more than 8.8 billion US-\$ had been signed, more than 
half of which (4.5 billion US-\$) related to investment projects of the German BASF ${ }^{6}$ and Bayer groups (Kreimeyer 2005; Stachels 2005; Shanghai Chemical Industry Park Development Co. 2007).

Producer-user linkages: At the time of our interviews, most industrial operations in the SCIP were not closely interlinked with each other or with other regional firms. Most bulk resources, especially crude oil, were imported from the Near East, Africa or Indonesia, and were shipped through the park's jetties. The interviews conducted indicated that the firms were also still heavily dependent upon corporate networks for supplies of specialty chemicals, know-how and other high-end services. In addition, direct linkages to foreign-owned chemical firms with customers in China were generally weak or non-existent. In particular, firms that were established as WFOEs tended to ship their products to specialized traders which, in turn, distributed these products to user industries. These were typically located in Hong Kong or in the city center of Shanghai. They operated as knowledge brokers by connecting otherwise unconnected firms, or as structural holes in the sense described by Burt (1995). We expect that this strong reliance on knowledge brokers could slow down learning processes based on producer-user interaction. According to one manager, decisions to invest in a WFOE project were generally based on former experience in China as well as the desire to avoid knowledge spillovers to Chinese competitors. The interviewee said: "We are convinced that we are [a] technology leader. We don't want to lose any know-how. So it was clear for us to do it in a $100 \%$... investment." Chinese firms also seemed to have customer relations that were relatively loose rarely focusing on aspects of learning and innovation. This appears to be an additional burden for the development of dynamic clusters.

The interviews conducted generally indicated that firms were only partially informed about other investment projects in the SCIP, or possibilities for future interaction. As such, local information flows seemed weak. We can expect, however, that local information flows through informal networks and producer-user relations might become stronger over time as more tenants will settle in the SCIP. Since the new projects involve different combinations of Chinese and foreign chemical groups, we anticipate that intended and unintended knowledge flows between these

\footnotetext{
${ }^{6}$ This investment project of BASF was, however, associated with substantial technical problems, which were a burden on the firm's 2006 profits in Asia (FR-online.de 2007).
} 
projects will develop, especially since some firms are simultaneously involved in projects with different partners. Many of our interviewees shared this view. Although "local buzz" was still low, and did not travel easily between the different locations in the region, other information flows, even between competing firms, did already exist. As our interviewees pointed out, these typically operated through private networks of foreign expatriates. This exchange did not, however, occur within the SCIP or its vicinity. Interestingly, it seemed to materialize mainly within the city of Shanghai and appeared to be cross-sectoral in character.

To support the training and qualification of employees, a plan was in place to establish branches of East China University of Science and Technology and the Shanghai Research Institute of Petrochemical Technology in the SCIP. German firms had started sponsoring the introduction of new programs in vocational schools that adopted the German dual training system, combining practical and conceptual knowledge. These and other projects aimed to secure a constant inflow of skilled labor. It is foreseeable that these developments will lead to a substantial increase in production capacities and employment. One of the park representatives suggested that the new investments will lead to a total chemical labor force in the region of 20,000 people in the future. The goal of including these training and research facilities in the park was also to stimulate future on-site research linkages. Altogether, the institutional conditions in the SCIP likely support the development of a new major center of chemical production, albeit not in the form of a fullyfledged industry cluster.

\section{Competitive Investments in Nanjing since the 1990 s and the Establishment of the Nanjing Chemical Industry Park (NCIP)}

The institutional settings for the development of the NCIP were quite different from those in Shanghai but also focused on large-scale development goals.

Park structure: The NCIP developed into the core of chemical production in the Nanjing region (Zhong 2007). It is located on the northern banks of the Yangtze River, about $30 \mathrm{~km}$ north of the city center (Figure 3 ). The chemical industry was the largest manufacturing sector of the region, adding up to about one third of the region's production value in manufacturing (Chen and Lu 2006). A total of about $45 \mathrm{~km}^{2}$ were reserved for the future growth of this industry (City of Nanjing 2007), large parts of which were not yet developed at the time of our research. Firms 
benefited from direct access to the Yangtze River, ${ }^{7}$ through which large shipments of crude oil and other resources were received. Harbor facilities allowed large ocean tankers of 25,000-50,000 tons to make their way through the Yangtze River (an extension to 100,000 tons was seemingly underway at the time of this research) (Krumberger 2005). ${ }^{8}$ The park also had access to Chinese oil fields through a pipeline system. The Luning Oil Pipeline was designed to transport 200 million tons of crude oil per year, and another pipeline from Ningbo was planned (City of Nanjing 2007). The labor market of the region benefited from access to several universities and research institutes located in the city of Nanjing, which offered specific programs in chemistry/chemical engineering. Aside from the SCIP, the NCIP was the only strategic chemical industry park in China that received approval by the central government.

Insert Figure 3 about here

Goal of development: Already before the economic opening policy, Nanjing was an important center of chemical/petrochemical production in China due to the activities of the formerly stateowned Sinopec group and its subsidiaries. The NCIP was established to complement and strengthen Sinopec's chemical production competencies, and support the development into a key petrochemical production base in China. As opposed to the SCIP, the NCIP aimed to maintain or strengthen the region's role within China and did not include a vision that went beyond national borders. Due to these goals, the park's development will likely support firms and production networks different from those in the SCIP. The NCIP was designed to focus on petrochemical and gas-based production, basic organic chemicals, polymer products and new materials (Nanjing Chemical Industry Park Co. 2005). As such, the park partially overlapped with the core areas of production in the SCIP. At the time of our research, this did not appear to be a major problem as demand was growing at a faster pace than production (Perlitz 2005). In the future, however, more

\footnotetext{
${ }^{7}$ This could, of course, also cause problems in the case of severe flooding, although the park authorities did not view this as a threat.

${ }^{8}$ Interviewees mentioned that the Yangtze River would allow larger shipments than the Hangzhou Bay where the water would not be deep enough. This would give the NCIP a competitive advantage over the SCIP, while other locational characteristics would not.
} 
competition between both chemical industry parks could be expected. The NCIP established a policy to attract foreign investors by granting initial tax exemptions and medium-term tax reductions, and by providing high-quality logistical infrastructure.

Firm structure and investments: In the mid 2000s, the industrial park hosted older plants of Chinese chemical and petrochemical firms, as well as more recent foreign investments by firms such as BOC (now Linde), BP, Celanese, DSM, Dystar, and Sasol Chemicals (Festel and Geng 2005). The NCIP was also surrounded by older Chinese firms such as the Nanjing Chemical Company, Yizheng Chemical Fiber Company and Jinling Petrochemical Corporation, the latter of which was located directly across the Yangtze River. The largest and most prospective investment project in the NCIP was the 50/50 joint venture between BASF and the Sinopec subsidiary Yangtze Petrochemical Co. (YPC), named BASF-YPC Company (BYC). BASF had already developed plans to establish a major steam cracker in China in the mid 1990s to produce ethylene and propylene from naphtha (Kurz and Schmidkonz 2005; Kreimeyer 2005). Building upon some earlier smaller joint investments in the region, the decision was made to invest in a large integrated production facility in Nanjing. As one observer explained, the original investment allowed the firm to check out and better understand the joint venture partner as well as overcome inconsistencies that could have created barriers to future cooperation. The construction activities began in 2000 and ended in 2005 when the new facilities were officially opened (Strohm 2005). ${ }^{9}$

The joint venture project occupied a territory of $2.2 \mathrm{~km}^{2}$ and involved investments of 2.9 billion US-\$. It produced exclusively for the Chinese market and did not engage in export activities (see, also, Tichauer 2005). ${ }^{10}$ In 2004, BASF had a total of twelve production sites and a labor force of 4,200 people in China (Kreimeyer 2005). The number of new jobs created through the Nanjing project remained moderate with only about 1,400 new positions (see, also, Perlitz 2005). It is interesting to note that to the idea of establishing a chemical industry park in the Nanjing region was not seriously pursued until this investment project had started. Interestingly, the site of

\footnotetext{
${ }^{9}$ One problem associated with the establishment of the park was that about 2,000 farmers had to be relocated from their former homes (Kurz and Schmidkonz 2005), a difficult process that had been underestimated and led to substantial protests among the local population, as one interviewee mentioned.

${ }^{10}$ This joint venture was part of BASF's plan to increase its overall share of sales in China and the Asia Pacific region by the year 2010 to $10 \%$ and $20 \%$, respectively (Strohm 2005; Perlitz 2005).
} 
BASF's new facilities was located outside of the originally designated territory of the NCIP. In most illustrations, however, it was shown as one integrated project (compare Figure 3), with consent from BASF. Although BASF-YPC cooperated closely with the park authorities and emphasized its commitment to the park's overall development, this signaled that it intended to remain independent from the park. Aside from the cracker, the firm operated numerous downstream production plants in areas related to polymers and complementary products. ${ }^{11}$

Similar to the SCIP, the growth of the chemical industry in Nanjing was driven by investments from German and other European multinationals, accompanied by formerly state-owned Chinese firms in large vertically-integrated joint ventures. In some industry branches such as petrochemicals, which were viewed as strategically important, market entry in the chemical industry was highly regulated by the central government (Perlitz 2005; Cheng and Bennett 2007). Having a Chinese joint venture partner, such as in the case of BASF, was also advantageous as firms were able to benefit from established distribution channels. Some older Chinese firms in the region, which ran into financial problems in the 1990s, were acquired by foreign producers providing them with new technologies and finance. One former state-owned corporation was, for instance, acquired by a German company. However, several years later the operations were sold to a South African chemical firm, as the local operations no longer fit the global core competencies of the German company. Originally relying on integrated production with little external supplier relations, the firm began to disintegrate and set up new service and supplier relations, in part with other firms in the region. Although the institutional conditions in the NCIP seemed quite supportive for further growth, it did not provide the basis for a similarly consistent development as in the SCIP, due to the heterogeneous structures and frictions involved.

Producer-user linkages: Consistent with this evaluation, our research indicated that the new chemical operations in the Nanjing region were not strongly linked with other regional firms through transactional networks. Both input and output linkages were largely national in character with little regional interaction. The structure of the industrial park resembled that of a sheer agglomeration of firms rather than an industry cluster in the sense of Porter (1990; 1998). Despite this, the growing concentration of chemical firms, including the operations of established Chinese

\footnotetext{
${ }^{11}$ Although the project contributed to high pollution levels in the region, the hope was expressed that BASF's responsible care initiative would increase overall environmental standards, safety regulations and worker's rights, thus contributing to a reduction in overall environmental damage and social disparities (Kurz and Schmidkonz 2005).
} 
firms in the wider region, provided new opportunities for the development of regional supplier networks, as some interviewees mentioned. Most firms still had strong input linkages with their foreign home base at the time our interviews were conducted.

A disadvantage of Nanjing seemed to be related to its limited local market potential. In comparison to this, chemical firms in southern China's Guangdong province and the Shanghai region were clearly in a better position. Nanjing operations had to concentrate a substantial part of their sales and marketing workforce and of their attention on these market regions. Despite some overlap in the production chain between the chemical parks in Nanjing and Shanghai, and the massive investments in Shanghai to become the leader in the Chinese chemical industry with international linkages, one should not overstate the competition between the industrial parks, as demand in the manufacturing sector in the Yangtze Delta region and other parts of China was rapidly growing. Nonetheless, some rivalry existed in the attraction of foreign direct investments and was repeatedly expressed in our interviews. ${ }^{12}$ In the mid 2000s, the SCIP was clearly more successful in attracting large investments than the NCIP. This seemed to be related to the fact that the chemical industry park in Nanjing had grown organically, producing some infrastructural shortages over time. In contrast, the SCIP was a greenfield investment which provided state-ofthe-art integrated services, large-scale infrastructure, and a modern environmental protection strategy to its tenants. Its institutional set-up was more coherent and offered advantages to a larger number of potential investors than that of the NCIP. In terms of the future research infrastructure, research linkages will likely be weaker in the NCIP than in the SCIP. Research linkages will likely develop with some universities and technical schools in the city of Nanjing. These conditions suggest that future growth could be somewhat slower than in the SCIP but would still be substantial. A well-developed cluster structure will not necessarily evolve under these conditions.

\footnotetext{
${ }^{12}$ A former leading manager in the German chemical industry suggested in a conversation that BASF might have easily rethought its location decision for Nanjing if it had been clear at that point that the SCIP was to be established.
} 


\section{The Development of the Ningbo Chemical Industry Zone (NCIZ) since 2003}

The NCIZ is again characterized by a rather different institutional configuration, opening different opportunities for regional growth compared to those analyzed in Shanghai and Nanjing. Park structure: The NCIZ was established in 2003 in the Ningbo region in Zhenhai on the south side of the Hangzhou Bay to support the establishment of a new chemical industry cluster (China Petroleum and Chemical Industry Association 2007c). The NCIZ is located $24 \mathrm{~km}$ west of the deep sea harbor and tank facilities in Beilun and $14 \mathrm{~km}$ northeast of the city of Ningbo (Figure 4). It has a scheduled size of $56.2 \mathrm{~km}^{2}$. At the time of our visit, $60 \%$ of the territory was still undeveloped, and about half of the remainder was occupied by a large older Sinopec petrochemical plant. The services available in the NCIZ included logistics, utilities, environmental protection and other support services (Ningbo Chemical Industry Zone Co. 2007a; 2007b). The industry zone also collaborated with a local research institute that offered a program for the training of chemical engineers.

Insert Figure 4 about here

$* * * * * * * * * * * * * * * * * * * * * * * * * * * * * * * * * *$

Goals of development: The NCIZ's original goal was to support the development of a value chain focused on the production of petrochemicals and downstream organic chemical production, similar to that of the SCIP and NCIP. To achieve this goal and generate cost advantages, a specific support policy for foreign investors was introduced. This included tax exemptions and reductions, as well as bonus payments for successful firms in the amount of 4 to $6 \%$ of their value added (Jiang 2004). The long-term goal was to establish one of the largest chemical industry zones in China and offer a full set of integrated services to its tenants. The idea behind the development of the industrial zone was to link new production capabilities with the Sinopec operations, which had expanded into the production of basic organic chemicals. As opposed to these original plans, the new tenants were neither linked with each other through input-output flows nor attracted to the zone based on cost advantages. Instead, they located there because the city of Ningbo had decided in the late 1990s that chemical production should be relocated from 
urban locations to the new chemical industry zone. As a consequence, about 20 to 25 firms had to move to the NCIZ.

The NCIZ was one of three chemical industry zones in a larger corridor of chemical production in the Yangtze Delta region that was originally viewed positively by the central government. As opposed to the chemical industry parks in Shanghai and Nanjing, the central government did not agree, however, to declare the NCIZ as a designated industrial park of strategic national importance. As a consequence, the chemical industry zone received different kinds of policy support, especially through the local government. The city government subsidized the zone's infrastructure to a large extent and actively supported the relocation of chemical firms from Ningbo.

Firm structure and investments: In 2007, the NCIZ hosted about 30 mostly small and mediumsized firms with a total labor force of 9,400 people. Two thirds of these were employed in the Sinopec petrochemical plant that had already been established in 1975. Overall, the NCIZ had not yet been successful in attracting major foreign investments based on cost advantages. In the area of petrochemical production, the joint venture LG Yongxin was established between the South Korean LG group and the Chinese firm Yongxin. Aside from this joint venture and a relatively small branch of the Dutch Akzo Nobel, the industry zone developed into a location of Chinese chemical firms. Although the development of the NCIZ was partly influenced by the presence of large state-owned firms or joint ventures, the majority of firms were started up independently based on substantial amounts of capital available in the region due to the successes of earlier entrepreneurial ventures of local Chinese business men. Access to these funds required that close linkages were developed with existing guanxi networks in the region. The impressions from our interviews and background knowledge about the province of Zhejiang suggest that such privately financed investment projects by regional business people might play an important role in the future.

A medium-sized producer of synthetic fibers exemplified this. The firm was a successful start-up and had 450 employees at the time of our visit. As one executive explained, it had received capital to acquire western technology and developed a large customer base due to strong personal networks. These networks were only partially regional in character, contributing to wider market access in Guangdong and the Yangtze Delta region. Another firm, a medium-sized producer of rubber products, was relocated to the industrial zone in 2001 . With a labor force of 525 people, 
the firm exported half of its production to industrial users in many different countries. The firm also had few supplier linkages in the region and province. Production was largely standardized and production facilities were relatively old. Similar to other firms in the zone, they did not include state-of-the-art technologies. Generally, the firm did not engage in close interaction with customers or suppliers from which ideas for future innovation could have developed.

Producer-user linkages: Most firms in the NCIZ were relatively small and did not form a value chain or parts thereof. They had no local customers and only limited market relations in the province. Our interviews also suggested that most Chinese chemical firms did not have close supplier linkages with other firms in the industry zone and the region. As such, the industrial zone had little resemblance with a cluster that is well developed along multiple dimensions (Bathelt and Zeng 2005). On the one hand, problems such as unresolved land use conflicts and environmental pollution, which caused local protests, put the NCIZ at a disadvantage compared to the development in Shanghai. The limited regional customer base and relatively large distances to other economic centers in the Yangtze Delta region were also viewed as disadvantages of Ningbo. To increase the potential for further growth, local authorities tried to foster a plan to establish a new pipeline to Nanjing to distribute petrochemical products. Yet, as one expert noted, it was unclear whether this investment would be realized under the new priorities of the central government. The development of the NCIZ was criticized by the provincial government because the firms created only a limited number of new jobs. Furthermore, tax revenues were largely transferred to Beijing and did not remain in the region. Most of the chemical firms that were founded prior to the NCIZ did not generate new jobs in the region.

On the other hand, however, the NCIZ also enjoyed a number of advantages compared to the industrial parks in Shanghai and Nanjing. First, it was open to investments smaller than those favored by the SCIP and the NCIP. Second, compared to the situation in Nanjing, local government support was much stronger, and environmental protection was likely to be given a higher priority. Finally, the completion of the Hangzhou Bay bridge, which is $36 \mathrm{~km}$ long and cuts down driving time between Shanghai and Ningbo from four to two hours, promised to become an important landmark for further economic development in the region, as it serves to strengthen traditional business ties between the regions (Chiang 2007). Ningbo might become part of the new periphery of Shanghai (compare Figure 1). This would lead to new opportunities for collaboration, as well as competition, between the chemical industry parks in both cities. 
Although the NCIZ was not as modern and well-developed as the SCIP, it had considerable growth potential especially because of its new link with Shanghai and the entrepreneurial local business culture related to the Wenzhou business model (Wei, Li and Wang 2007). In terms of research linkages, plans to support or create such linkages at the regional level did not exist. Any development toward the establishment of such linkages would, thus, likely have to be stimulated in a decentralized fashion by individual firms. At the time of our research, investment activities had come to a standstill related to the institutional conditions at hand. The development of a cluster structure appeared unrealistic at that point.

\section{Conclusions: Toward the Development of New Industry Clusters in the Chemical Industry?}

This paper provides compelling evidence of the enormous growth potential in the "old economy" of the Yangtze Delta region, especially as it relates to the chemical industry and its new industrial parks. This growth is a consequence of the large agglomeration of industrial users in the Shanghai, Jiangsu and Zhejiang provinces. The region boasts deep sea harbors and oil pipelines, which enable easy access to the resources and raw materials required for chemical production. Even though production capacities were substantially extended in the $2000 \mathrm{~s}$, the demand for chemical products was, in many product segments, still higher than domestic supply. Particularly in the area of specialty chemicals, China was still a large importer of chemical products (Perlitz 2005; Table 1). In the Yangtze Delta region, this growth had led to developments that were both complements and rivals. The three chemical industry parks in Shanghai, Nanjing and Ningbo, which serve as the focal points of this paper, were designed to become world-scale facilities, each having a projected size of 30 to $55 \mathrm{~km}^{2}$. As summarized in Table 5, the SCIP, NCIP and NCIZ were characterized by different institutional set-ups and structures, leading to different growth trajectories. Our argument is that these divergent paths were shaped by the institutional arrangements of particular business models which were dominant in these regions, contributing to different growth trajectories:

$* * * * * * * * * * * * * * * * * * * * * * * * * * * * * * * * * *$

Insert Table 5 about here

$* * * * * * * * * * * * * * * * * * * * * * * * * * * * * * * * * *$ 
- $\quad$ Nanjing, the earliest of the three parks, was influenced by the Sunan model, which is characteristic of the southern parts of the Jiangsu province (Wei 2002; Ong 2007). In this model, which became important in the 1980s, economic development is primarily led by collective or state-owned enterprises and a corresponding mixture of ownership forms. This model incorporates a very active role for the state in economic development. In the case of the NCIP, this leading role was combined with the integration of foreign firms through joint venture enterprises. The goal was to ensure the effective allocation and use of the national resource base. Consequently, petrochemical production was closely linked to oil supplies from Chinese sources. Imports that were shipped through the Yangtze River also played an important role.

- In the early 1990s, with an increasing market orientation and reduction of state control in economic development, another business model, the Wenzhou model, became very successful in the Zhejiang province. It is characterized and driven by successful local private enterprises, associated firm formation processes and a reduced role of the state (Wei, Li and Wang 2007; Ong 2007). This model strongly shaped the growth trajectory of Ningbo. The development of the NCIZ was, in large part, based on investments by private enterprises which were driven by cost efficiency incentives. Financial resources were secured by means of local guanxi networks through which the potential influence of the central and provincial government was further reduced. ${ }^{13}$

- In contrast, the design of Shanghai's chemical industry park was led by the successful Pudong model, which became dominant in the late 1990s. This model is characterized by a strong orientation towards foreign investment and associated technology transfers aiming at stimulating locally-based innovation processes (Wang 1996). It actively seeks to integrate and stimulate foreign-owned and joint venture enterprises to drive regional economic development through technology transfers and business networks with technology-oriented Chinese firms. To accomplish this, Chinese re-migrants are actively integrated into the local economy (e.g. Sternberg and Müller 2005; Saxenian 2006). The goal is to embed foreign business cultures and practices within the community of Chinese

\footnotetext{
${ }^{13}$ There are, however, also disadvantages to the Wenzhou model, as it is associated with low wage levels, a low degree of technological sophistication and illegal transfers of intellectual property through its guanxi networks.
} 
firms. It remains unclear, however, to what degree the Pudong model can be implemented in the chemical industry.

In general, the industrial parks investigated in this paper were established with the goal of forming clusters of interlinked operations in the area of petrochemicals and organic chemicals. Although development was still at an early stage at the time of our research, it was foreseeable that most industrial park developers would not stick closely to the goal of developing an extended chemical value chain. Whether the chemical industry parks would have the potential to develop into closely connected industry clusters was, therefore, questionable, supporting our first hypothesis. Our research indicated that linkages between the tenants of the industrial parks were an exception. Furthermore, regional supplier and customer linkages were also weak, and material flows between new foreign branches and older Chinese production sites hardly existed. Foreign production facilities were still strongly committed to their corporate networks for securing the supply of specialty chemicals and engineering know-how. Strategic decisions tended to be made at the firms' global headquarters, which were often located in Europe. This could change in the future, however, if more opportunities for regional networks develop from the continued investments in new operations. Although the direct employment effects of the new chemical operations remained relatively small, because of the high degree of automation of these facilities, regional labor markets were beginning to develop that were specialized in a broad range of chemical fields. They included a wide scope and scale of university graduates and skilled production workers. This development was supported by specialized training programs at regional universities and technical schools and was, in part, actively supported by foreign multinationals which funded the implementation of new programs.

Of course, rapid economic growth also put a great deal of stress on natural resources and could threaten overall environmental quality. As older high-pollution chemical firms were increasingly being shut down or modernized and new foreign investment projects with modern technology completed, the overall pollution levels due to chemical production might not necessarily increase in the three regions. In this respect, it would be misleading to assume that the new chemical industry parks contributed substantially to increasing environmental problems. Due to limited employment outcomes combined with potentially negative environmental effects, it remained unclear whether the chemical industry parks in Shanghai, Nanjing and Ningbo would grow to their envisioned full scales. 
Under these circumstances, the central government reduced its financial support for further investments in the chemical industry in the late 2000s. Because land in the Yangtze Delta region became increasingly scarce and too valuable for large-scale resource-intensive industries, the goal was developed to foster the growth of the chemical industry in different parts of China. The central government would rather prioritize high-technology industries and modern service sectors in the Yangtze Delta region. Whether this would be feasible appeared, however, questionable. It also remained unclear in which other parts of China the chemical industry would be located. One has to keep in mind that chemical products are often dangerous and costly to transport. It is unrealistic that virtually all chemical products would be shipped to the Yangtze Delta region from other countries or other locations in China. Under the conditions of fast economic growth combined with climate change, it might be necessary to develop an integrated and coordinated environmentally-sensitive policy approach to support the development of the chemical industry, rather than trying to abandon it altogether. Furthermore, the effects of "peak oil" will likely drastically increase transportation cost. Since much of the oil resources needed for this development must be imported by ship, it would likely become too expensive to transport these bulk commodities to new inland locations and the chemical products, in turn, back to the coastal markets. The growth prospects of the three chemical industry parks are, thus, still unclear. The parks likely differ substantially and would be highly contingent upon the government's future decisions regarding the chemical industry:

- $\quad$ First, if the government decides to continue and extend its economic opening policy and free-market focus, Shanghai would likely have the strongest growth potential of the three parks. The SCIP is strongly linked with international markets through corporate ties of foreign investors and their producer-user networks. Furthermore, the developers purposely designed the SCIP to become an international hub for distribution and corporate control in Southeast Asia.

- Second, if the government, in contrast, establishes a different policy aimed at strengthening Chinese raw material producers through interventions and trade barriers, Nanjing could have the largest growth potential. Policy-makers and developers of the NCIP are already concerned with extending and protecting Nanjing's tradition as the primary center of petrochemical production in China and building upon domestic resource access and linkage networks. 
- $\quad$ Third, the outcome would again differ if the government cuts its financial subsidies for investments in the chemical industry altogether. In this case, Ningbo could have the highest growth potential of the three industrial parks, as its development is less dependent on such financial support. The relocation of chemical firms to the NCIZ and regional start-up processes are largely dependent on the capability of the firms to mobilize capital within the region.

Overall, these observations support our second hypothesis - namely, that what might be viewed as highly complementary investments could, upon closer analysis, be an indication of diverging regional visions of economic growth, leading to a new interregional division of labor in the chemical industry. These developments would likely be closely linked to the different institutional conditions at hand, and in turn support regional specialization.

\section{Acknowledgements}

This paper was presented at the Second Global Conference on Economic Geography in Beijing, June $25-28,2007$. It draws upon research which was jointly conducted by both authors, who contributed equally to this paper. We would like to thank the Special Issue Editors Yifei Sun and Ronald Kalafsky for their strong support and for providing stimulating comments. In addition, we appreciate the input from Lynette Ong and three anonymous referees. We also benefited strongly from the excellent research support by Heiner Depner, Ulrich Dewald, Rachael Gibson, Nicole Kogler, Fei Li, Yuefang Si, Peter Süß, Fei Wang and Qin Xiao for which we are very grateful. Furthermore, we would like to thank Volker Langbein for providing us with important initial contacts in the chemical industry in China. We are especially indebted to all chemical industry experts, policy makers and company representatives from Chinese, German and other foreign chemical firms in China for being very generous in providing us with information and giving us their views of the development of the chemical industry in the Yangtze Delta region. This research was, in part, supported by the Deutsche Forschungsgemeinschaft (German Research Council), National Natural Science Foundation of China, East China Normal University and the Canada Research Chair in Innovation and Governance at the University of Toronto. 


\section{References}

Atherton, A., \& Johnston, A. (2008). Clusters formation from the "bottom-up": A process

perspective. In C. Karlsson (Ed.), Handbook of research on cluster theory (pp. 93-113).

Cheltenham, Northampton (MA): Edward Elgar.

Bathelt, H. (1997). Chemiestandort Deutschland. Technologischer Wandel, Arbeitsteilung und geographische Strukturen in der Chemischen Industrie (German chemical industry: Technological change, the division of labor and geographical structure). Berlin: Edition Sigma - Bohn.

Bathelt, H. (2005). Chanye jiqun yanjiu de xin shijiao (Toward a reconceptualization of clusters). World Regional Studies - Shijie Dili Yanjiu, 14(1), 1-8.

Bathelt, H., \& Glückler, J. (2003). Wirtschaftsgeographie: Ökonomische Beziehungen in räumlicher Perspektive (Economic geography: Economic relations in spatial perspective). 2nd ed., Stuttgart: UTB - Ulmer.

Bathelt, H., Malmberg, A., \& Maskell, P. (2004). Clusters and knowledge: Local buzz, global pipelines and the process of knowledge creation. Progress in Human Geography, 28, 3156.

Bathelt, H., \& Zeng, G. (2005). Von ressourcenabhängigen, unvernetzten Industrien zu Industrieclustern? Das Beispiel der südchinesischen Großstadt Nanning (From resourcedependent, isolated industrial firms to industrial clusters? The example of Nanning, Southern China). Zeitschrift für Wirtschaftsgeographie, 49, 1-22.

Burt, R. (1995). Structural holes: The social structure of competition. Cambridge (MA), London: Harvard University Press.

Cheng, J., \& Bennett, D. (2007). Success strategies in the Chinese chemical industry: A survey and case study investigations. Journal of Chinese Economic and Business Studies, 5(2), 91-112.

Chen, J., \& Lu, Y. (2006). Jianli Nanjing-Yizheng daxing shihua jidi de kexingxing ji celue yanjiu (Development strategy for the chemical industry basis in Nanjing-Yizheng). Tequ Jingji (Special Zone Economy), 9/2006, 295-296.

Chiang, L. (2007). Building links to prosperity. Toronto Star, July 10, B7. 
China Petroleum and Chemical Industry Association (2006). Shiyiwu huaxue gongye keji fazhan gangyao yaodian (Report on the outline of the eleventh five-year plan for the chemical industry technology in China). Zhongguo Shiyou He Huagong Biaozhun Yu Zhiliang (China Petroleum and Chemical Standard and Quality), 2, 3-7.

China Petroleum and Chemical Industry Association (2007a). China chemical industry yearbook. Beijing: China National Chemical Information Center.

China Petroleum and Chemical Industry Association (2007b). Zhongguo shiyou he huaxue gongye jingji yunxing 2006nian huigu ji 2007nian zhanwang (Review of China's oil and chemical industries in 2006 and prospects for 2007). Guoji Shiyou Jingji (International Petroleum Economics), 2, 37-45.

China Petroleum and Chemical Industry Association (2007c).Zhejiangsheng shiyou he huexue gongye shiyiwu fazhan zhidao yijian (Key points in the eleventh five-year plan for the chemical industry in the Zhejiang province). Zhejiang Huaxue (Zhejiang Chemical Industry), 38(2), 3-7.

City of Nanjing (2007). Investment in Nanjing. Nanjing.

http://218.94.6.170/cps/site/nanjing/English/index(i1).html. Accessed 29 May 2007.

Cao, Y., Qian, Y., \& Weingast, B. R. (1999). From federalism, Chinese style to privatization, Chinese style. Economics of Transition, 7, 103-131.

Depner, H., \& Bathelt, H. (2005). Exporting the German model: The establishment of a new automobile industry cluster in Shanghai. Economic Geography, 81, 53-81.

Dong, K. (2007). Jingji quanqiuhua Beijing xia zhongguo shihua gongye quwei yanhua ji jizhi yanjiu (Research on the spatial structure and evolution of the petrochemical industry in China under globalization). MA Thesis, Shanghai: Department of Human Geography, East China Normal University.

Enright, M. J. (2003). Regional clusters: What we know and what we should know. In J. Bröcker, D. Dohse, \& R. Soltwedel (Eds.), Innovation clusters and interregional competition (pp. 99-129). Berlin, Heidelberg: Springer.

Feldman, M. P., \& Francis, J. L. (2004). Homegrown solutions: Fostering cluster formation. Economic Development Quarterly, 18, 127-137. 
Festel, G., \& Geng, Y. (2005). Chemical industry parks in China. In G. Festel, A. Kreimeyer, U. Oels, \& M. v. Zedtwitz (Eds.), The chemical and pharmaceutical industry in China: Opportunities and threats to foreign companies (pp. 53-62). Heidelberg: Springer.

FR-online.de (2007). BASF legt für 2006 Rekordwerte bei Umsatz und Gewinn vor (BASF presents new records in sales and profits for 2006). February 22.

Hang, Y. (2007). Zhongguo shiyou he huaxue gongye yu zhanwang (Review and prospects of China's oil and chemical industries in China). Huagong Zhiliang (Quality for Chemical Industry), 2, 14-18.

Henn, S. (2006). Regionale Cluster in der Nanotechnologie: Entstehung, Eigenschaften, Handlungsempfehlungen (Regional clusters of nanotechnology: Genesis, characteristics, policy implications). Frankfurt/Main: Lang.

Hodgson, G. M. (1988). Economics and institutions: A manifesto for a modern institutional economics. Cambridge: Polity Press.

Jiang, B. (2004). Zhen zai fazhen zhang de Ningbo huaxue ciongye qu (Development of the Ningbo chemical industry zone). Zhongguo Shiyou He Huagong (China Petroleum and Chemical Industry), 5, 73-77.

Jiangsu Bureau of Statistics (1997-2007). Jiangsu statistical yearbook. Beijing: China Statistics Press.

Kreimeyer, A. (2005). Swimming ahead of the shoal - The history of BASF in greater China. In G. Festel, A. Kreimeyer, U. Oels, \& M. v. Zedtwitz (Eds.), The chemical and pharmaceutical industry in China: Opportunities and threats to foreign companies (pp. 159-170). Heidelberg: Springer.

Krumberger, O. (2005). Establishing a competitive production network in Asia. In G. Festel, A. Kreimeyer, U. Oels, \& M. v. Zedtwitz (Eds.), The chemical and pharmaceutical industry in China: Opportunities and threats to foreign companies (pp. 171-179). Heidelberg: Springer.

Kurz, S., \& Schmidkonz, C. (2005). The impact of direct investment of BASF in Nanjing, China on the sustainable development of the region. Study of the Deutsche Gesellschaft für Technische Zusammenarbeit (GTZ). Nanjing. 
Malmberg, A., \& Maskell, P. (2002). The elusive concept of localization economies: Towards a knowledge-based theory of spatial clustering. Environment and Planning A, 34, 429-449.

Malmberg, A., \& Power, D. (2003). (How) do (firms in) clusters create knowledge? Paper presented at the Danish Research Unit on Industrial Dynamics summer conference "Creating, sharing and transferring knowledge. The role of geography, institutions and organizations". Copenhagen. http://www.druid.dk/conferences/summer2003/Papers/MALMBERG_POWER.pdf. Accessed 19 January 2005.

Martin, R., \& Sunley, P. (2003). Deconstructing clusters: Chaotic concept or policy panacea? Journal of Economic Geography, 3, 5-35.

Maskell, P., \& Lorenzen, M. (2004). The cluster as market organisation. Urban Studies, 41, 9911009.

McCann, P. (2008). Agglomeration economies. In C. Karlsson (Ed.), Handbook of research on cluster theory (pp. 23-38). Cheltenham, Northampton (MA): Edward Elgar.

Miles, M. B., \& Huberman, A. M. (1994). Qualitative data analysis: An expanded sourcebook. 2nd ed., Thousand Oaks (CA): Sage.

Mu, J. (2006). Changjiang sanjiaozhou shihua gongye kongjian jiegou yanhua yanjiu (Research on the spatial structure of the petrochemical industry in the Yangtze delta region). MA Thesis, Shanghai: Department of Human Geography, East China Normal University.

Mueller, H. (2005). Activities of European chemical companies in China. In G. Festel, A. Kreimeyer, U. Oels, \& M. v. Zedtwitz (Eds.): The chemical and pharmaceutical industry in China: Opportunities and threats to foreign companies (pp. 23-46). Heidelberg: Springer.

Nanjing Chemical Industry Park Co. (2005). Investment guide 2005. Brochure. Nanjing. National Bureau of Statistics of China (1984a-2007a). China statistical yearbook. Beijing: China Statistics Press.

National Bureau of Statistics of China (1988b-2007b). China industry economy statistical yearbook. Beijing: China Statistics Press. 
National Bureau of Statistics of China (1998c). China labour statistical yearbook 1998. Beijing: China Statistical Publishing House.

National Bureau of Statistics of China (1999c). Comprehensive statistical data and materials on 50 years of new China. Beijing: China Statistics Press.

National Bureau of Statistics of China (2004c). Comprehensive statistical data and materials on 55 years of new China. Beijing: China Statistics Press.

National Bureau of Statistics of China (2007c). China trade and external economic statistical yearbook. Beijing: China Statistics Press.

National Bureau of Statistics of China (2007d). China labour statistical yearbook 2007. Beijing: China Statistical Publishing House.

Ningbo Chemical Industry Zone Co. (2007a). Investment guide. Brochure. Ningbo.

Ningbo Chemical Industry Zone Co. (2007b). Ningbo chemical industry zone. Ningbo. http://www.chemzone.net:9081/wps/portal. Accessed 17 June 2007.

North, D. C. (1990). Institutions, institutional change and economic performance. Cambridge: Cambridge University Press.

Ong, L. H. (2007). Between developmental and clientelist states: Explaining rural industrialization in China. Paper presented at the Department of Political Science series "Politics at Noon". Toronto: University of Toronto.

Perlitz, U. (2005). Chemieindustrie in China: international auf der Überholspur (Chemical industry in China: Overtaking internationally). Deutsche Bank Research: Aktuelle Themen 333: China Spezial. Frankfurt/Main.

Pinch, S., Henry, N., Jenkins, M., \& Tallmann, S. (2003). From "industrial districts" to "knowledge clusters": A model of knowledge dissemination and competitive advantage in industrial agglomerations. Journal of Economic Geography, 3, 373-388.

Porter, M. E. (1990). The competitive advantage of nations. New York: Free Press.

Porter, M. E. (1998). Clusters and the new economics of competition. Harvard Business Review, 76(November-December), 77-90. 
Saxenian, A. (2006). The new argonauts: Regional advantage in a global economy. Cambridge (MA): Harvard University Press.

Schiller, B. (2008). From boom to bust: The rise and fall of China's stock market. Toronto Star, June $12, \mathrm{~B} 1 \& \mathrm{~B} 5$.

Setterfield, M. (1993). A model of institutional hysteresis. Journal of Economic Issues, 27, 755774.

Shanghai Bureau of Statistics (1984-2007). Shanghai statistical yearbook. Beijing: China Statistics Press.

Shanghai Chemical Industry Park Development Co. (2004). Shanghai chemical industry park. Shanghai. http://www.scip.com.cn. Accessed 13 October 2004.

Shanghai Chemical Industry Park Development Co. (2005). Shanghai chemical industry park. Brochure. Shanghai.

Shanghai Chemical Industry Park Development Co. (2007). Shanghai chemical industry park. Shanghai. http://www.scip.com.cn. Accessed 29 May 2007.

Shanghai Economic Commission, Shanghai Municipal Statistics Bureau, \& Shanghai

Development Park Association (2004). 2004 Shanghai development park annual (in Chinese). Shanghai.

Shanghai Economic Commission, Shanghai Municipal Statistics Bureau, \& Shanghai

Development Park Association (2007). 2007 Shanghai development park statistical manual (in Chinese). Shanghai.

Silverman, D. (2001). Interpreting qualitative data: Methods for analysing talk, text and interaction. 2nd ed., London, Thousand Oaks (CA): Sage.

Stachels, E. (2005). Bayer - A multinational committed to China. In G. Festel, A. Kreimeyer, U. Oels, \& M. v. Zedtwitz (Eds.), The chemical and pharmaceutical industry in China: Opportunities and threats to foreign companies (pp. 181-188). Heidelberg: Springer.

Sternberg, R., \& Müller, C. (2005). Return migration in regional innovation systems. Asian Journal of Technology Innovation, 13, 71-95. 
Strohm, T. (2005). BASF setzt auf Milliarden-Projekte in China (BASF builds upon billion-Euro projects in China). Frankfurter Rundschau, September 28, 11.

Sun, J., \& Gu. C. (2004). Jiangsu Yanjiang kaifa yanjiu (Development of the area along the Yangtze river in Jiangsu). Changjiang Liuyu Ziyuan Yu Huanjin (Resources and Environment in the Yangtze Basin), 13(5), 403-407.

Tichauer, P. (2005). Chemie für die Turnschuhgeneration: Das Joint Venture von BASF und Sinopec wird zum drittgrößten Chemiestandort der Welt (Chemistry for the sports shoes generation: The joint venture between BASF and Sinopec becomes the third largest in the world). Asia Bridge, 1/2005, 23.

Wan, Z. (2008). Oil's not well. China Daily - China Business Weekly, June 16-22, 1 \& 3.

Wang, X. (1996). Pudong kaifa moshi ying cong "tudi gundong" zhuanxiang "shuishou gundong" (The basis of the Pudong model of development: From land to tax reference). Tansuo Yu Zhengming (Explorations and Free Views), 1996.1, 45-46.

Wei, Y. D. (2002). Beyond the Sunan model. Environment and Planning A, 34, 1725-1747.

Wei, Y. D., Li, W., \& Wang, C. (2007). Restructuring industrial districts, scaling up regional development: A study of the Wenzhou model, China. Economic Geography, 83, 421-444.

Wu, J. (2005). Sikao yu huiying: Zhongguo gongyehua de jueze (Reflection and response: Choosing the way to Chinese industrialization). Xueshu Yuekan (Academic Monthly), 12, $38-45$.

Xin, Z. (2008). Factor costs up by $8.2 \%$. China Daily, June 12, 1.

Yang, Y. (2006). Huaxue gongye buju yu zhongguo chengshi jingji fazhan Yanjing (The location of the chemical industry in the context of the Chinese urban economy). MA Thesis, Shanghai: Department of Human Geography, East China Normal University.

Zeng, G. (2000). The financial crisis in Asia and the modification of economic structure in Shanghai (in Chinese). Asian Geographer, 19, 37-48.

Zeng, G. (2001). Shi gongye buju tiaozhen chu Tan (Research on the modification of industrial spatial distribution in Shanghai). Geographical Research, 20(3), 330-337. 
Zhejiang Bureau of Statistics (1999-2007). Zhejiang statistical yearbook. Beijing: China Statistics Press.

Zhong, H. (2007). Shiyiwu kaiju de Jiangsu huaxue gongye (The development of the chemical industry in the Jiangsu province in the eleventh five-year period). Jiangsu Huagong (Jiangsu Chemical Industry), 35(3), 20-24. 
Figure 1: Geography of the Yangtze Delta Region, 2007

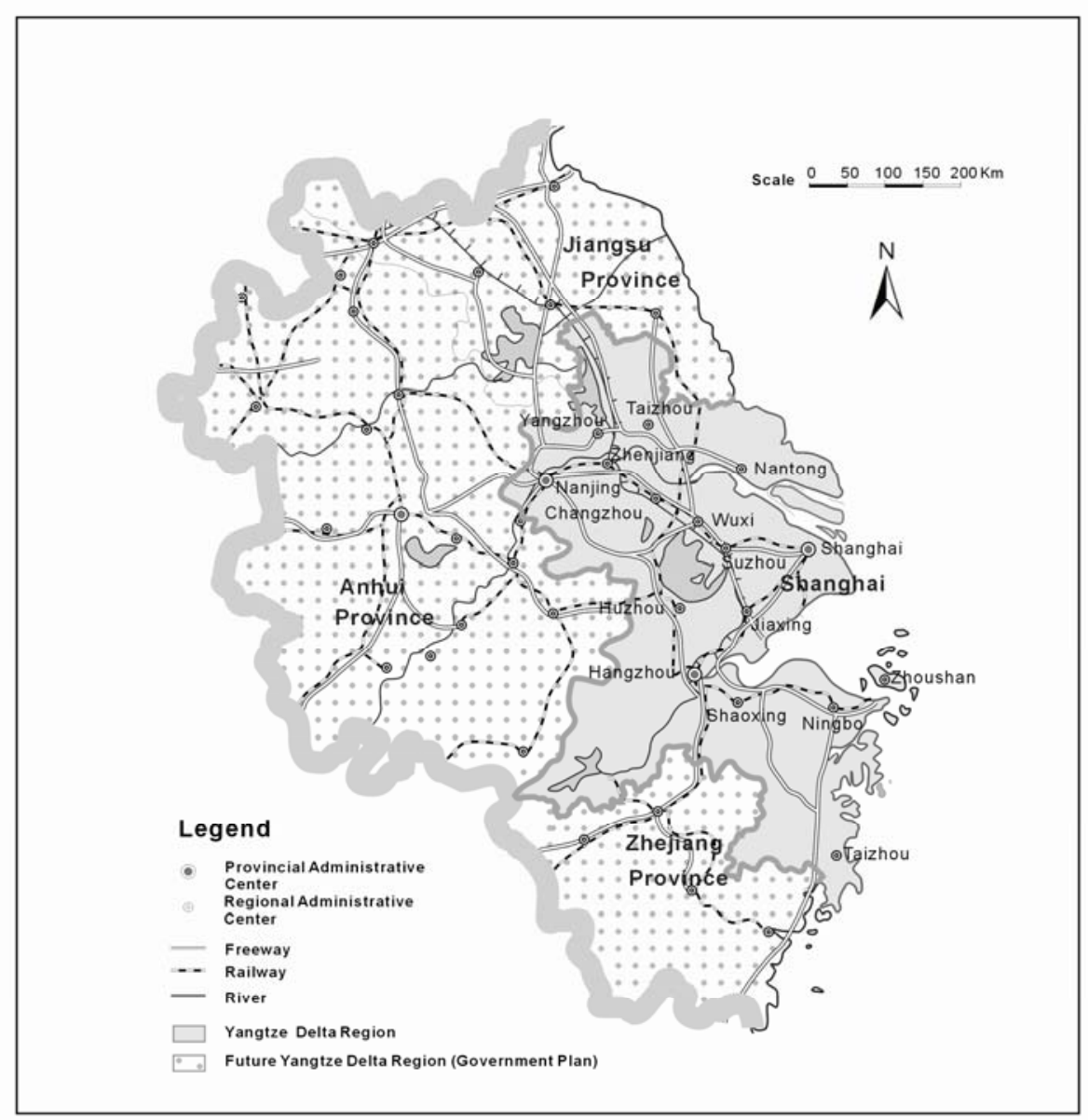


Table 1: Development of Employment, Gross Production Values and Import and Export Values of the Chemical Industry in China, 1980-2006 (Source: Computed from China Petroleum and Chemical Industry Association 2007a; National Bureau of Statistics of China 1984a-2007a; 1988b-2007b; 1999c; 2004c; 2007c)

\begin{tabular}{|c|c|c|c|c|}
\hline Year & $\begin{array}{l}\text { Number of } \\
\text { employees } \\
\text { (million) }\end{array}$ & $\begin{array}{c}\text { Gross production } \\
\text { value (billion } \\
\text { Yuan) }{ }^{1)} \\
\end{array}$ & $\begin{array}{l}\text { Import value } \\
\text { (billion Yuan) }\end{array}$ & $\begin{array}{l}\text { Export value } \\
\text { (billion Yuan) }\end{array}$ \\
\hline 1980 & n.a. ${ }^{2)}$ & n.a. & 2.91 & 1.12 \\
\hline 1981 & n.a. & n.a. & 2.61 & 1.34 \\
\hline 1982 & 3.13 & 65.90 & 2.94 & 1.20 \\
\hline 1983 & 3.18 & 74.11 & 3.18 & 1.25 \\
\hline 1984 & 3.27 & 83.03 & 4.24 & 1.36 \\
\hline 1985 & 3.96 & 109.40 & 4.47 & 1.36 \\
\hline 1986 & 4.16 & 121.63 & 3.77 & 1.73 \\
\hline 1987 & 4.44 & 193.84 & 5.01 & 2.24 \\
\hline 1988 & 4.63 & 247.71 & 9.14 & 2.90 \\
\hline 1989 & 4.74 & 300.13 & 7.56 & 3.20 \\
\hline $1990^{3)}$ & 6.97 & 325.76 & 6.65 & 3.73 \\
\hline 1991 & 7.84 & n.a. & 9.28 & 3.82 \\
\hline 1992 & 7.51 & 469.92 & 11.16 & 4.35 \\
\hline 1993 & 7.68 & 612.67 & 9.70 & 4.62 \\
\hline 1994 & 7.96 & 803.43 & 12.13 & 6.24 \\
\hline 1995 & 8.19 & 955.67 & 17.30 & 9.09 \\
\hline 1996 & 8.14 & 1072.42 & 18.11 & 8.88 \\
\hline 1997 & 7.87 & 1163.98 & 19.30 & 10.23 \\
\hline 1998 & 6.22 & 1142.02 & 20.20 & 10.32 \\
\hline 1999 & 5.77 & 1423.02 & 24.03 & 10.37 \\
\hline 2000 & 5.35 & 1623.31 & 30.21 & 12.10 \\
\hline 2001 & 4.94 & 1698.52 & 32.10 & 13.35 \\
\hline 2002 & 4.77 & 1905.78 & 39.04 & 15.33 \\
\hline 2003 & 4.80 & 2039.81 & 48.98 & 19.58 \\
\hline 2004 & 4.65 & 2874.01 & 65.47 & 26.36 \\
\hline 2005 & 4.93 & 4248.36 & 77.73 & 35.77 \\
\hline 2006 & 5.00 & 5293.52 & 87.05 & 44.53 \\
\hline
\end{tabular}

Notes: ${ }^{1)} 1$ US- $\$=8$ Yuan (2005 and before $) / 7.5$ Yuan $(2006) .{ }^{2)}$ n.a. = data not available. ${ }^{3)}$ Data prior to 1990 only encompasses state-owned and collective enterprises; since then private firms are also included. 
Table 2: Development of Gross Production Values of the Chemical Industry in the Yangtze Delta Region by Province, 1983-2006 (Sources: Computed from Jiangsu Bureau of Statistics 1997-2007; National Bureau of Statistics of China 1984a-2007a; 1988b-2007b; Shanghai Bureau of Statistics 1984-2007; Zhejiang Bureau of Statistics 1999-2007)

\begin{tabular}{|c|c|c|c|c|c|}
\hline \multirow[b]{2}{*}{ Year } & \multicolumn{4}{|c|}{$\begin{array}{l}\text { Gross production value by province } \\
\text { (billion Yuan })^{1)}\end{array}$} & \multirow[b]{2}{*}{ China } \\
\hline & Shanghai & Jiangsu & Zhejiang & $\begin{array}{l}\text { Yangtze Delta } \\
\text { region }\end{array}$ & \\
\hline 1983 & 8.90 & 7.63 & 3.41 & 19.94 & 74.11 \\
\hline 1984 & 9.63 & 8.88 & 4.15 & 22.66 & 83.03 \\
\hline 1985 & 14.82 & 10.43 & 5.21 & 30.46 & 109.40 \\
\hline 1986 & 14.90 & 14.09 & 6.55 & 35.54 & 121.63 \\
\hline 1987 & 17.44 & 20.74 & 8.50 & 46.68 & 193.84 \\
\hline 1988 & 21.18 & 28.67 & 15.82 & 65.67 & 247.71 \\
\hline 1989 & 24.84 & 35.52 & 15.60 & 75.96 & 300.13 \\
\hline 1990 & 26.88 & 40.58 & 16.54 & 84.00 & 325.76 \\
\hline 1992 & 36.86 & 63.84 & 27.43 & 128.13 & 469.92 \\
\hline 1993 & 44.83 & 80.99 & 35.15 & 160.97 & 612.67 \\
\hline 1994 & 58.89 & 108.69 & 48.66 & 216.24 & 803.43 \\
\hline 1995 & 70.11 & 128.53 & 58.77 & 257.41 & 955.67 \\
\hline 1996 & 76.22 & 122.06 & 70.20 & 268.48 & 1072.42 \\
\hline 1997 & 81.22 & 145.67 & 75.62 & 302.51 & 1163.98 \\
\hline 1998 & 92.06 & 155.97 & 85.15 & 333.18 & 1142.02 \\
\hline 1999 & 103.06 & 181.87 & 106.61 & 391.54 & 1423.02 \\
\hline 2000 & 120.50 & 210.65 & 129.84 & 460.99 & 1623.31 \\
\hline 2001 & 122.25 & 226.99 & 139.31 & 488.55 & 1698.52 \\
\hline 2002 & 133.23 & 263.23 & 169.58 & 566.04 & 1905.78 \\
\hline 2003 & 136.46 & 313.99 & 208.06 & 658.51 & 2039.81 \\
\hline 2004 & 202.51 & 436.72 & 346.65 & 985.88 & 2874.01 \\
\hline 2005 & 264.00 & 593.35 & 447.55 & 1304.90 & 4248.36 \\
\hline 2006 & 309.10 & 740.03 & 553.93 & 1603.06 & 5293.51 \\
\hline
\end{tabular}

Note: ${ }^{1)} 1$ US- $\$=8$ Yuan (2005 and before)/7.5 Yuan (2006). 
Table 3: Regional Distribution of Chemical Industry Employment in China, 1997 and 2006 (Source: Computed from National Bureau of Statistics of China 1998c; 2007d)

\begin{tabular}{|c|c|c|c|}
\hline \multirow[b]{2}{*}{ Province } & \multicolumn{3}{|c|}{ Share of national employment (\%) } \\
\hline & 1997 & 2006 & $\begin{array}{l}\text { Difference } \\
1997-2006\end{array}$ \\
\hline Shandong & 7.8 & 9.9 & 2.1 \\
\hline Guangdong & 5.4 & 7.7 & 2.3 \\
\hline Jiangsu & 7.9 & 7.4 & -0.5 \\
\hline Zhejiang & 3.9 & 6.6 & 2.7 \\
\hline Henan & 6.0 & 5.6 & -0.4 \\
\hline Liaoning & 8.3 & 5.4 & -2.9 \\
\hline Hebei & 5.1 & 4.8 & -0.3 \\
\hline Fujian & 2.8 & 4.5 & 1.7 \\
\hline Hubei & 4.6 & 4.0 & -0.6 \\
\hline Sichuan & 3.8 & 3.9 & 0.1 \\
\hline Shanxi & 3.7 & 3.8 & 0.1 \\
\hline Heilongjiang & 3.8 & 3.8 & 0.0 \\
\hline Shanghai & 3.7 & 3.6 & -0.1 \\
\hline Hunan & 4.3 & 2.9 & -1.4 \\
\hline Beijing & 2.2 & 2.6 & 0.4 \\
\hline Tianjin & 2.6 & 2.5 & -0.1 \\
\hline Anhui & 3.5 & 2.3 & -1.2 \\
\hline Shaanxi & 1.9 & 2.3 & 0.4 \\
\hline Jilin & 4.0 & 2.2 & -1.8 \\
\hline Jiangxi & 2.4 & 2.1 & -0.3 \\
\hline Gansu & 1.8 & 1.9 & 0.1 \\
\hline Guangxi & 1.8 & 1.8 & 0.0 \\
\hline Yunnan & 1.7 & 1.7 & 0.0 \\
\hline Guizhou & 1.1 & 1.6 & 0.5 \\
\hline Chongqing & 2.2 & 1.4 & -0.8 \\
\hline Xinjiang & 1.0 & 1.3 & 0.3 \\
\hline Inner Mongolia & 1.5 & 1.1 & -0.4 \\
\hline Ningxia & 0.6 & 0.6 & 0.0 \\
\hline Qinghai & 0.3 & 0.4 & 0.1 \\
\hline Hainan & 0.3 & 0.3 & 0.0 \\
\hline Tibet & 0.0 & 0.0 & 0.0 \\
\hline Chinese total & 100.0 & 100.0 & - \\
\hline (number of employees) & $(7,870,000)$ & $(5,002,000)$ & - \\
\hline
\end{tabular}


Table 4: Share of Gross Production Values in the Yangtze Delta Region of the Chinese

Total, by Province and Chemical Branch 2006 (Source: Computed from Jiangsu Bureau of Statistics 2007; National Bureau of Statistics of China 2007a; Shanghai Bureau of Statistics 2007; Zhejiang Bureau of Statistics 2007)

\begin{tabular}{|c|c|c|c|c|c|}
\hline \multirow[b]{2}{*}{ Chemical branch } & \multicolumn{4}{|c|}{$\begin{array}{l}\text { Share of the Chinese gross production value of the } \\
\text { Chinese total, by chemical branch (\%) }\end{array}$} & \multirow[b]{2}{*}{ China } \\
\hline & Shanghai & Jiangsu & Zhejiang & $\begin{array}{l}\text { Yangtze Delta } \\
\text { region }\end{array}$ & \\
\hline $\begin{array}{l}\text { Raw chemical materials and } \\
\text { chemical products }\end{array}$ & 6.5 & 19.3 & 7.7 & 33.5 & 100.0 \\
\hline $\begin{array}{l}\text { Medical and pharmaceutical } \\
\text { products }\end{array}$ & 4.7 & 10.5 & 9.7 & 24.9 & 100.0 \\
\hline Chemical fibers & 1.5 & 31.2 & 38.7 & 71.4 & 100.0 \\
\hline Rubber products & 5.7 & 12.8 & 10.2 & 28.7 & 100.0 \\
\hline Plastic products & 6.2 & 12.7 & 17.6 & 36.5 & 100.0 \\
\hline $\begin{array}{l}\text { Petroleum processing, coke } \\
\text { products and processing of } \\
\text { nuclear fuels }\end{array}$ & 6.1 & 5.1 & 5.5 & 16.7 & 100.0 \\
\hline
\end{tabular}


Figure 2: Spatial Setting of the Shanghai Chemical Industry Park (SCIP) (Source: Developed from Shanghai Chemical Industry Park Development Co. 2005; 2007)

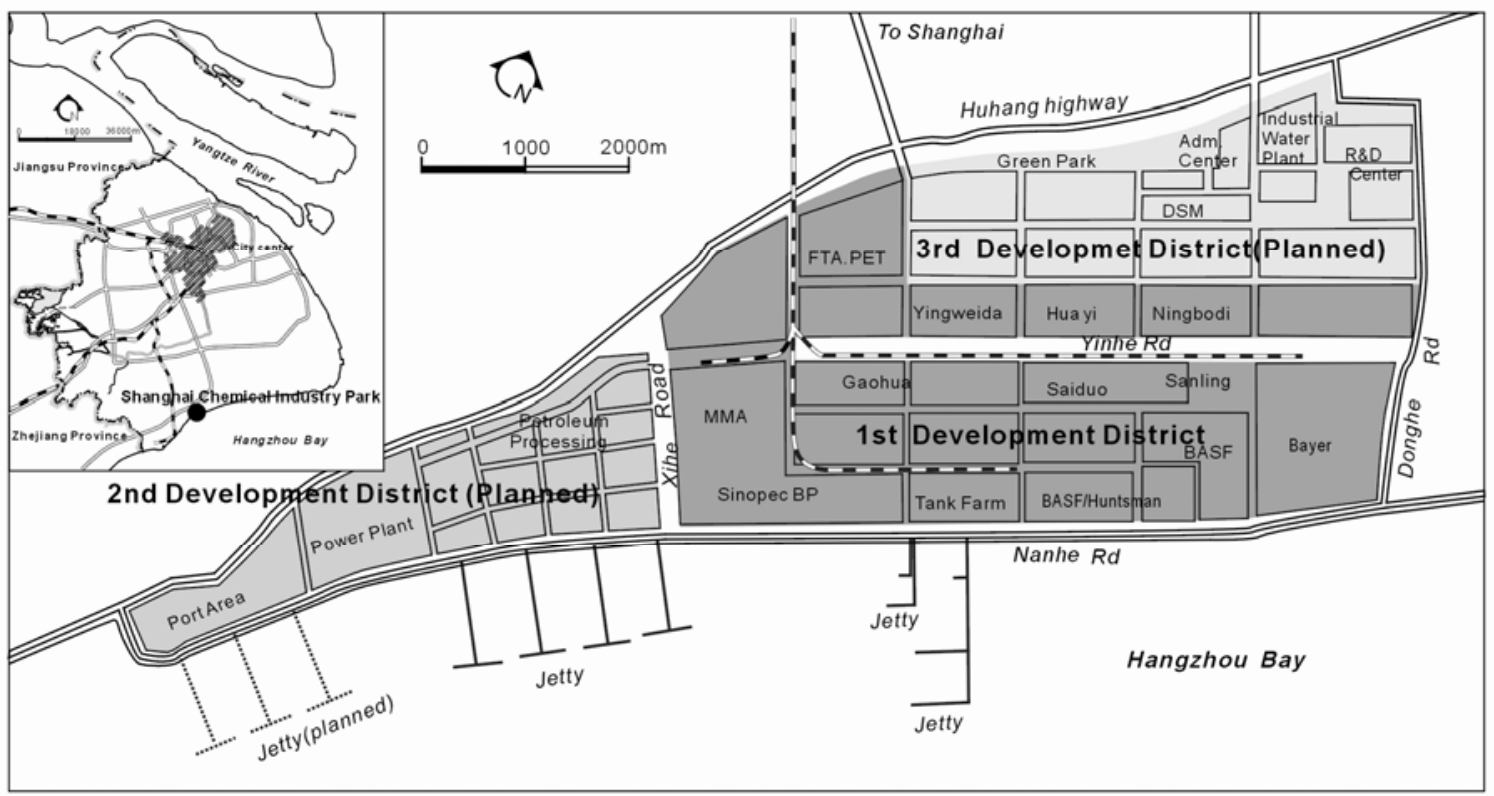


Figure 3: Spatial Setting of the Nanjing Chemical Industry Park (NCIP) (Source:

Developed from Nanjing Chemical Industry Park Co. 2005; Kurz and Schmidkonz 2005)

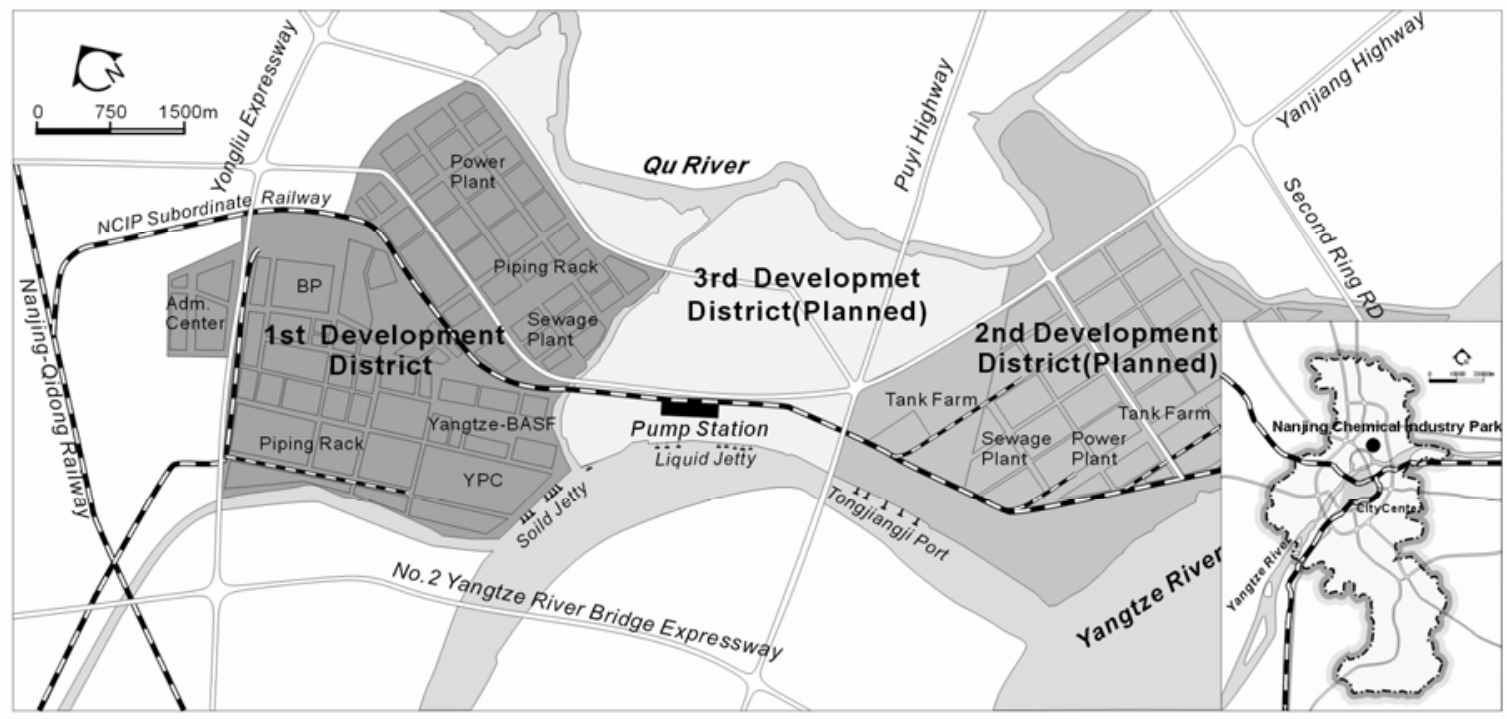


Figure 4: Spatial Setting of the Ningbo Chemical Industry Zone (NCIZ) (Source: Developed from Ningbo Chemical Industry Zone Co. 2007a; 2007b)

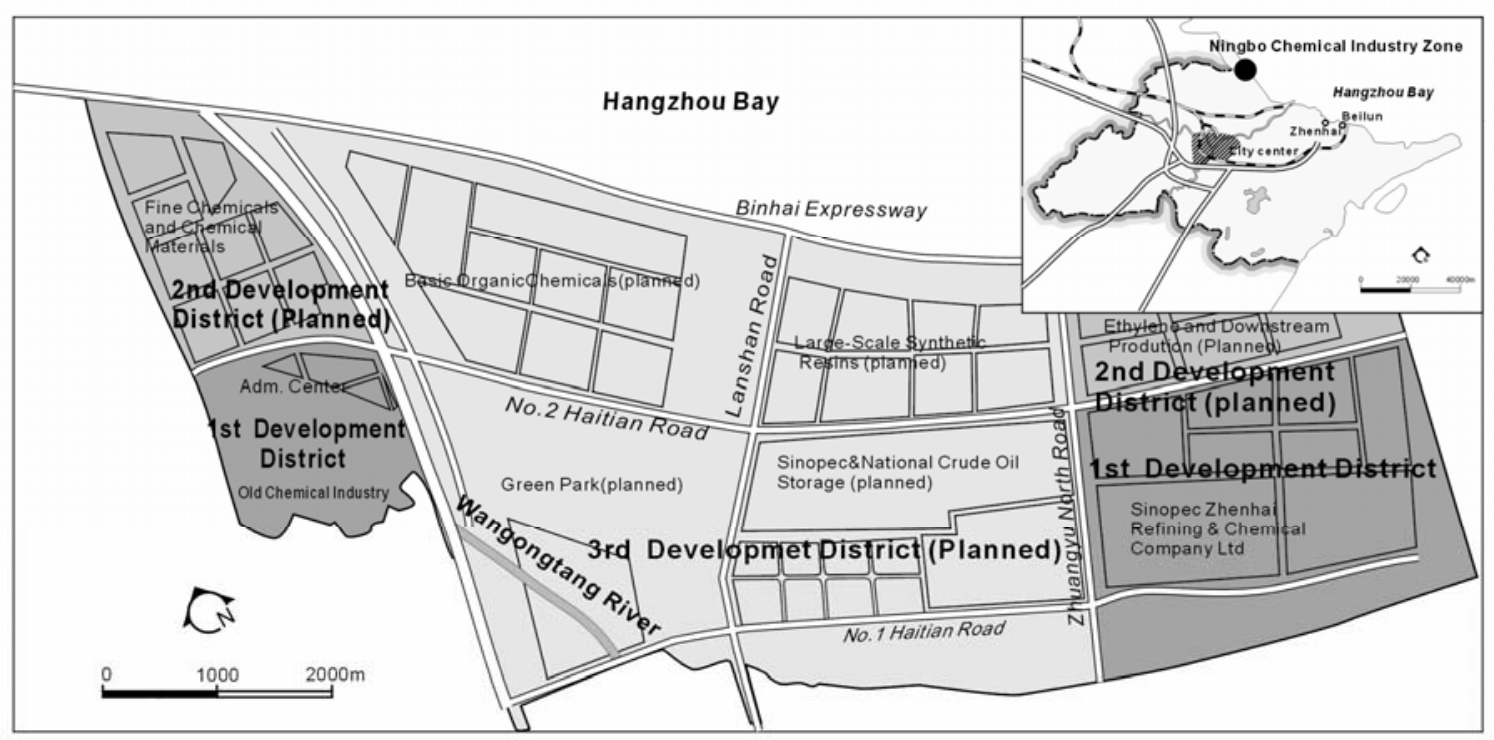


Table 5: Industrial Structure and Institutional Set-up of the Chemical Industry Parks in Shanghai, Nanjing and Ningbo, 2008 (Source: Survey Results)

\begin{tabular}{|c|c|c|c|}
\hline $\begin{array}{l}\text { Characteristics } \\
\text { of industrial } \\
\text { structure }\end{array}$ & $\begin{array}{l}\text { Shanghai Chemical Industry } \\
\text { Park (SCIP) }\end{array}$ & $\begin{array}{l}\text { Nanjing Chemical } \\
\text { Industry Park (NCIP) }\end{array}$ & $\begin{array}{l}\text { Ningbo Chemical Industry } \\
\text { Zone (NCIZ) }\end{array}$ \\
\hline $\begin{array}{l}\text { Business } \\
\text { model }\end{array}$ & $\begin{array}{l}\text { Pudong model (late 1990s): } \\
\text { orientation towards foreign } \\
\text { investments/technologies; } \\
\text { local implementation of } \\
\text { foreign business culture }\end{array}$ & $\begin{array}{l}\text { Sunan model (1980s): } \\
\text { development primarily led } \\
\text { by collective/state-owned } \\
\text { enterprises; effective } \\
\text { use/allocation of national } \\
\text { resources }\end{array}$ & $\begin{array}{l}\text { Wenzhou model (early } \\
\text { 1990s): development led } \\
\text { by local private } \\
\text { enterprises; market- } \\
\text { oriented cost-efficient } \\
\text { investments based on local } \\
\text { guanxi networks }\end{array}$ \\
\hline $\begin{array}{l}\text { Dominant } \\
\text { ownership } \\
\text { structure }\end{array}$ & $\begin{array}{l}\text { Joint venture firms/wholly } \\
\text { foreign-owned enterprises }\end{array}$ & $\begin{array}{l}\text { Mixture of collective/ } \\
\text { state-owned firms and } \\
\text { foreign enterprises }\end{array}$ & $\begin{array}{l}\text { Local private enterprises/ } \\
\text { few large state-owned } \\
\text { firms/joint ventures }\end{array}$ \\
\hline Product focus & $\begin{array}{l}\text { Petrochemicals/organic } \\
\text { chemicals and downstream } \\
\text { processing (value chain } \\
\text { focus) }\end{array}$ & $\begin{array}{l}\text { Petrochemicals/organic } \\
\text { chemicals with } \\
\text { downstream linkages (no } \\
\text { planned value chain } \\
\text { development) }\end{array}$ & $\begin{array}{l}\text { Mixture of specialty } \\
\text { chemicals/organic } \\
\text { chemicals }\end{array}$ \\
\hline $\begin{array}{l}\text { Goal of } \\
\text { establishment }\end{array}$ & $\begin{array}{l}\text { Greenfield development of } \\
\text { integrated chemical park } \\
\text { according to western ideals/ } \\
\text { prototypes, built around a } \\
\text { value-chain concept }\end{array}$ & $\begin{array}{l}\text { On-site modernization of } \\
\text { state-owned enterprises }\end{array}$ & $\begin{array}{l}\text { Relocation of existing } \\
\text { inner-city chemical firms }\end{array}$ \\
\hline $\begin{array}{l}\text { State of } \\
\text { development }\end{array}$ & $\begin{array}{l}\text { Early state of development; } \\
\text { initial sophisticated } \\
\text { investments completed; fast } \\
\text { growth }\end{array}$ & $\begin{array}{l}\text { Dual structure: established } \\
\text { firms and initial park } \\
\text { development; medium } \\
\text { growth with potential }\end{array}$ & $\begin{array}{l}\text { Early state of develop- } \\
\text { ment; less sophisticated } \\
\text { but profitable firms; } \\
\text { medium growth }\end{array}$ \\
\hline $\begin{array}{l}\text { Origins of } \\
\text { bulk resources }\end{array}$ & $\begin{array}{l}\text { Imports from Near East; } \\
\text { Africa; Indonesia }\end{array}$ & $\begin{array}{l}\text { Pipeline flows from } \\
\text { Shandong; imports from } \\
\text { Near East }\end{array}$ & $\begin{array}{l}\text { Imports from Near East; } \\
\text { Africa; Indonesia (smaller } \\
\text { quantities) }\end{array}$ \\
\hline $\begin{array}{l}\text { Regional } \\
\text { linkages }\end{array}$ & $\begin{array}{l}\text { Adjustments of foreign } \\
\text { operations to Chinese } \\
\text { settings; few local material } \\
\text { linkages }\end{array}$ & $\begin{array}{l}\text { State-driven networks; few } \\
\text { local material linkages }\end{array}$ & $\begin{array}{l}\text { Guanxi networks/ } \\
\text { financial linkages; few } \\
\text { local material linkages }\end{array}$ \\
\hline $\begin{array}{l}\text { International } \\
\text { linkages }\end{array}$ & $\begin{array}{l}\text { Higher degree of } \\
\text { internationalization; access } \\
\text { to foreign corporate } \\
\text { networks }\end{array}$ & $\begin{array}{l}\text { Medium } \\
\text { internationalization; access } \\
\text { to foreign and national } \\
\text { corporate/state networks }\end{array}$ & $\begin{array}{l}\text { Limited } \\
\text { internationalization; } \\
\text { primarily local enterprises }\end{array}$ \\
\hline $\begin{array}{l}\text { Research/ } \\
\text { advanced } \\
\text { services }\end{array}$ & $\begin{array}{l}\text { Research activities } \\
\text { envisioned, including on-site } \\
\text { university/college branches }\end{array}$ & $\begin{array}{l}\text { Research not as important; } \\
\text { but off-site linkages to } \\
\text { universities/colleges in the } \\
\text { city }\end{array}$ & $\begin{array}{l}\text { No detailed plans to create } \\
\text { research linkages } \\
\text { envisioned }\end{array}$ \\
\hline
\end{tabular}

